Cochrane Database of Systematic Reviews

\title{
Effect of testing for cancer on cancer- and venous thromboembolism (VTE)-related mortality and morbidity in people with unprovoked VTE (Review)
}

Robertson L, Yeoh SE, Stansby G, Agarwal R

Robertson L, Yeoh SE, Stansby G, Agarwal R.

Effect of testing for cancer on cancer- and venous thromboembolism (VTE)-related mortality and morbidity in people with unprovoked VTE. Cochrane Database of Systematic Reviews 2017, Issue 8. Art. No.: CD010837.

DOI: 10.1002/14651858.CD010837.pub3.

www.cochranelibrary.com

Effect of testing for cancer on cancer- and venous thromboembolism (VTE)-related mortality and morbidity in people with unprovoked VTE (Review)

Copyright @ 2017 The Cochrane Collaboration. Published by John Wiley \& Sons, Ltd. 


\section{TABLE OF CONTENTS}

HEADER

ABSTRACT

PLAIN LANGUAGE SUMMARY

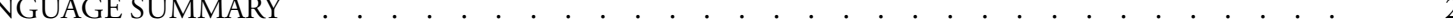

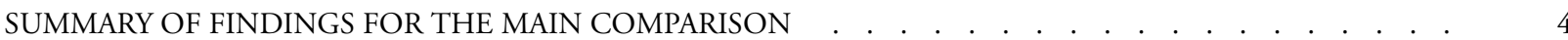

BACKGROUND . . . . . . . . . . . . . . . . . . . . . . . . . . . . . . . . . . . . . 7

OBJECTIVES . . . . . . . . . . . . . . . . . . . . . . . . . . . . . . . . . . . . . . . . . . . .

METHODS . . . . . . . . . . . . . . . . . . . . . . . . . . . . . . . . . . . . . . 8

RESULTS . . . . . . . . . . . . . . . . . . . . . . . . . . . . . . . . . . . . . . . . . 10

Figure 1. . . . . . . . . . . . . . . . . . . . . . . . . . . . . . . . . . . . . 11

Figure 2. . . . . . . . . . . . . . . . . . . . . . . . . . . . . . . . . . . . . .

Figure 3. . . . . . . . . . . . . . . . . . . . . . . . . . . . . . . . . . . . . . . . . . . . . .

ADDITIONAL SUMMARY OF FINDINGS . . . . . . . . . . . . . . . . . . . . . . . . . . . . . . .

DISCUSSION . . . . . . . . . . . . . . . . . . . . . . . . . . . . . . . . . . . . . . . . . . 20

AUTHORS' CONCLUSIONS . . . . . . . . . . . . . . . . . . . . . . . . . . . . . . . . . . . . . . .

ACKNOWLEDGEMENTS . . . . . . . . . . . . . . . . . . . . . . . . . . . . . . . . . . . . 21

REFERENCES . . . . . . . . . . . . . . . . . . . . . . . . . . . . . . . . . . . . . . . . . . . . . 22

CHARACTERISTICS OF STUDIES . . . . . . . . . . . . . . . . . . . . . . . . . . . . . . . . . . . . . 23

DATA AND ANALYSES . . . . . . . . . . . . . . . . . . . . . . . . . . . . . . . . . . . . . . . . . . . . . . . 32

Analysis 1.1. Comparison 1 Extensive tests versus tests at the physician's discretion, Outcome 1 Cancer-related mortality. 33

Analysis 1.2. Comparison 1 Extensive tests versus tests at the physician's discretion, Outcome 2 Characteristics of diagnosed cancer: type of cancer. . . . . . . . . . . . . . . . . . . . . . . . . . . . . . . . . . . . . . . . . . . . . . . 34

Analysis 1.3. Comparison 1 Extensive tests versus tests at the physician's discretion, Outcome 3 Characteristics of diagnosed cancer: stage of cancer. . . . . . . . . . . . . . . . . . . . . . . . . . . . . . . . . . . . . . . . . . . . . .

Analysis 1.4. Comparison 1 Extensive tests versus tests at the physician's discretion, Outcome 4 Frequency of underlying cancer diagnosis.

Analysis 2.1. Comparison 2 Standard testing plus PET/CT scanning versus standard testing alone, Outcome 1 All-cause mortality.

Analysis 2.2. Comparison 2 Standard testing plus PET/CT scanning versus standard testing alone, Outcome 2 Cancerrelated mortality.

Analysis 2.3. Comparison 2 Standard testing plus PET/CT scanning versus standard testing alone, Outcome 3 Venous thromboembolism-related morbidity.

Analysis 2.4. Comparison 2 Standard testing plus PET/CT scanning versus standard testing alone, Outcome 4 Characteristics of diagnosed cancer: type of cancer. . . . . . . . . . . . . . . . . . . . . . . . . . . . . .

Analysis 2.5. Comparison 2 Standard testing plus PET/CT scanning versus standard testing alone, Outcome 5 Characteristics of diagnosed cancer: stage of cancer.

Analysis 2.6. Comparison 2 Standard testing plus PET/CT scanning versus standard testing alone, Outcome 6 Frequency of an underlying cancer diagnosis. . . . . . . . . . . . . . . . . . . . . . . . . . . . . . . . . . . . 445

APPENDICES . . . . . . . . . . . . . . . . . . . . . . . . . . . . . . . . . . . . . 45

WHAT'S NEW . . . . . . . . . . . . . . . . . . . . . . . . . . . . . . . . . . . . . . 52

HISTORY . . . . . . . . . . . . . . . . . . . . . . . . . . . . . . . . . . . . . . . 52

CONTRIBUTIONS OF AUTHORS . . . . . . . . . . . . . . . . . . . . . . . . . . . . . . . . . . . . . . . $\quad . \quad 53$

DECLARATIONS OF INTEREST . . . . . . . . . . . . . . . . . . . . . . . . . . . . . . . . . . . . . . . 53

SOURCES OF SUPPORT . . . . . . . . . . . . . . . . . . . . . . . . . . . . . . . . . . . . . . . . . . . . . . . . .

DIFFERENCES BETWEEN PROTOCOL AND REVIEW . . . . . . . . . . . . . . . . . . . . . . . . . . . . . . 54

INDEX TERMS . . . . . . . . . . . . . . . . . . . . . . . . . . . . . . . . . . . . . 54

Effect of testing for cancer on cancer- and venous thromboembolism (VTE)-related mortality and morbidity in people with unprovoked 
[Intervention Review]

\title{
Effect of testing for cancer on cancer- and venous thromboembolism (VTE)-related mortality and morbidity in people with unprovoked VTE
}

\author{
Lindsay Robertson ${ }^{1}$, Su Ern Yeoh $^{2}$, Gerard Stansby $^{3}$, Roshan Agarwal ${ }^{4}$ \\ ${ }^{1}$ Department of Vascular Surgery, Freeman Hospital, Newcastle upon Tyne, UK. ${ }^{2}$ College of Medicine and Veterinary Medicine, The \\ University of Edinburgh, Edinburgh, UK. ${ }^{3}$ Northern Vascular Centre, Freeman Hospital, Newcastle upon Tyne, UK. ${ }^{4}$ Department of \\ Oncology, Northampton General Hospital NHS Trust, Northampton, UK
}

Contact address: Lindsay Robertson, Department of Vascular Surgery, Freeman Hospital, Newcastle upon Tyne Hospitals NHS Foundation Trust, High Heaton, Newcastle upon Tyne, NE7 7DN, UK. lindsay.robertson@nuth.nhs.uk, lindsay.robertson@ed.ac.uk.

Editorial group: Cochrane Vascular Group.

Publication status and date: Edited (no change to conclusions), published in Issue 11, 2017.

Citation: Robertson L, Yeoh SE, Stansby G, Agarwal R. Effect of testing for cancer on cancer- and venous thromboembolism (VTE)related mortality and morbidity in people with unprovoked VTE. Cochrane Database of Systematic Reviews 2017, Issue 8. Art. No.: CD010837. DOI: 10.1002/14651858.CD010837.pub3.

Copyright (C) 2017 The Cochrane Collaboration. Published by John Wiley \& Sons, Ltd.

\begin{abstract}
A B S T R A C T
Background

Venous thromboembolism (VTE) is a collective term for two conditions: deep vein thrombosis (DVT) and pulmonary embolism (PE). A proportion of people with VTE have no underlying or immediately predisposing risk factors and the VTE is referred to as unprovoked. Unprovoked VTE can often be the first clinical manifestation of an underlying malignancy. This has raised the question of whether people with an unprovoked VTE should be investigated for an underlying cancer. Treatment for VTE is different in cancer and non-cancer patients and a correct diagnosis would ensure that people received the optimal treatment for VTE to prevent recurrence and further morbidity. Furthermore, an appropriate cancer diagnosis at an earlier, potentially curative stage could avoid the risk of cancer progression and thus lead to improvements in cancer-related mortality and morbidity. This is an update of a review first published in 2015.
\end{abstract}

\section{Objectives}

To determine whether testing for undiagnosed cancer in people with a first episode of unprovoked VTE (DVT of the lower limb or PE) is effective in reducing cancer and VTE-related mortality and morbidity and to determine which tests for cancer are best at identifying treatable cancers early.

\section{Search methods}

For this update, the Cochrane Vascular Information Specialist (CIS) searched the Specialised Register (16 February 2017). In addition, the CIS searched the Cochrane Register of Studies CENTRAL (2017, Issue 1). We searched trials registries (February 2017) and checked the reference lists of relevant articles.

\section{Selection criteria}

Randomised and quasi-randomised trials in which people with an unprovoked VTE were allocated to receive specific tests for cancer or clinically indicated tests only were eligible for inclusion in this review. Primary outcomes included all-cause mortality, cancer-related mortality and VTE-related mortality.

Effect of testing for cancer on cancer- and venous thromboembolism (VTE)-related mortality and morbidity in people with unprovoked 


\section{Data collection and analysis}

Two review authors independently selected studies, assessed quality and extracted data. We resolved any disagreements by discussion.

\section{Main results}

Four studies with 1644 participants met the inclusion criteria (two studies in the original review and two in this update). Two studies assessed the effect of extensive tests versus tests at the physician's discretion) while the other two studies assessed the effect of standard testing plus positron emission tomography (PET)/computed tomography (CT) scanning versus standard testing alone. For extensive tests versus tests at the physician's discretion, the quality of the evidence was low due to risk of bias (early termination of the studies). When comparing standard testing plus PET/CT scanning versus standard testing alone, the quality of evidence was moderate due to a risk of detection bias. The quality of the evidence was downgraded further when detection bias was present in one study with a low number of events.

When comparing extensive tests versus tests at the physician's discretion, pooled analysis on two studies showed that testing for cancer was consistent with either a benefit or no benefit on cancer-related mortality (odds ratio (OR) $0.49,95 \%$ confidence interval (CI) 0.15 to $1.67 ; 396$ participants; 2 studies; $\mathrm{P}=0.26$; low quality evidence). One study (201 participants) showed that, overall, malignancies were less advanced in extensively tested participants than in participants in the control group. In total, 9/13 participants diagnosed with cancer in the extensively tested group had a T1 or T2 stage malignancy compared to $2 / 10$ participants diagnosed with cancer in the control group (OR 5.00, 95\% CI 1.05 to 23.76; $\mathrm{P}=0.04$; low quality evidence). There was no clear difference in detection of advanced stages between extensive tests versus tests at the physician's discretion: one participant in the extensively tested group had stage T3 compared with four participants in the control group ( $\mathrm{OR} 0.25,95 \%$ CI 0.03 to 2.28 ; P = 0.22; low quality evidence). In addition, extensively tested participants were diagnosed earlier than control group (mean: 1 month with extensive tests versus 11.6 months with tests at physician's discretion to cancer diagnosis from the time of diagnosis of VTE). Extensive testing did not increase the frequency of an underlying cancer diagnosis (OR 1.32, 95\% CI 0.59 to 2.93; 396 participants; 2 studies; P = 0.50; low quality evidence). Neither study measured all-cause mortality, VTE-related morbidity and mortality, complications of anticoagulation, adverse effects of cancer tests, participant satisfaction or quality of life.

When comparing standard testing plus PET/CT screening versus standard testing alone, standard testing plus PET/CT screening was consistent with either a benefit or no benefit on all-cause mortality (OR 1.22, 95\% CI 0.49 to 3.04; 1248 participants; 2 studies; P = 0.66; moderate quality evidence), cancer-related mortality (OR 0.55, 95\% CI 0.20 to $1.52 ; 1248$ participants; 2 studies; $\mathrm{P}=0.25$; moderate quality evidence) or VTE-related morbidity (OR 1.02, 95\% CI 0.48 to $2.17 ; 854$ participants; 1 study; P = 0.96; moderate quality evidence). With regards to stage of cancer, there was no clear difference for detection of early (OR 1.78, 95\% 0.51 to 6.17; 394 participants; 1 study; $\mathrm{P}=0.37$; low quality evidence) or advanced (OR 1.00, 95\% CI 0.14 to 7.17; 394 participants; 1 study; $\mathrm{P}=1.00$; low quality evidence) stages of cancer. There was also no clear difference in the frequency of an underlying cancer diagnosis (OR 1.71, 95\% CI 0.91 to $3.20 ; 1248$ participants; 2 studies; $\mathrm{P}=0.09$; moderate quality evidence). Time to cancer diagnosis was 4.2 months in the standard testing group and 4.0 months in the standard testing plus PET/CT group $(\mathrm{P}=0.88)$. Neither study measured VTErelated mortality, complications of anticoagulation, adverse effects of cancer tests, participant satisfaction or quality of life.

\section{Authors' conclusions}

Testing for cancer in people with unprovoked VTE may lead to earlier diagnosis of cancer at an earlier stage of the disease. However, there is currently insufficient evidence to draw definitive conclusions concerning the effectiveness of testing for undiagnosed cancer in people with a first episode of unprovoked VTE (DVT or PE) in reducing cancer and VTE-related morbidity and mortality. The results could be consistent with either benefit or no benefit. Further good-quality large-scale randomised controlled trials are required before firm conclusions can be made.

\section{PLAIN LANGUAGE SUMMARY}

Effect of testing for cancer (on cancer and blood clot-related death and illness) in people with unprovoked blood clots in the legs and lungs

\section{Background}

Venous thromboembolism (VTE) refers to blood clots in leg veins (known as deep venous thrombosis (DVT)), which can travel to the lungs (causing pulmonary embolism (PE)). PE can often be fatal. Signs of DVT include pain and swelling of the leg while signs of

Effect of testing for cancer on cancer- and venous thromboembolism (VTE)-related mortality and morbidity in people with unprovoked 2 VTE (Review)

Copyright $\odot 2017$ The Cochrane Collaboration. Published by John Wiley \& Sons, Ltd. 
PE include breathlessness and chest pain. Risk factors for VTE include surgery, prolonged bed rest, trauma, family history, pregnancy and blood deficiencies. However, sometimes a VTE happens for no apparent reason (it is unprovoked). In such people, an undetected cancer may be the cause of the VTE. This has raised the question of whether people with an unprovoked VTE should be investigated for underlying cancer. This is potentially important as the management of VTE in people with and without cancer differs. A cancer diagnosis would ensure that people received the optimal treatment to reduce the risk of another VTE. A diagnosis could also lead to the cancer being treated earlier, at a more curable stage.

\section{Study characteristics and key results}

This review assessed whether testing for undiagnosed cancer in people with a first unprovoked VTE (DVT or PE) was effective in reducing cancer and VTE-related illness and death. We found four studies with 1644 participants (current to February 2017). Two studies compared extensive cancer tests with tests carried out at the physician's discretion and two studies compared cancer tests plus scanning with cancer tests alone. Combining the results of the two studies showed that extensive testing had no effect on the number of cancer-related deaths. Additionally, extensive testing did not identify more people with cancer. However, extensive testing did identify cancers at an earlier stage (approximately 10 months earlier) and cancers were less advanced in people in the extensive testing group than in people in the group with tests carried out at the physician's discretion. Neither study looked at the number of deaths due to any cause, deaths and illness associated with VTE, side effects of cancer tests, side effects of VTE treatment or participant satisfaction. Two studies that compared tests plus scanning with tests alone showed that adding computed tomography scanning had little or no effect on the number of deaths, cancer-related deaths, illness associated with VTE or did it identify more people with cancer, or showed a clear difference in time to diagnosis or stages of cancer diagnosed. Neither study looked at illness associated with VTE, side effects of cancer tests, side effects of VTE treatment, participant satisfaction or quality of life.

\section{Quality of the evidence}

When comparing extensive tests versus tests at the physician's discretion, the quality of the evidence was low due to bias caused by two of the studies stopping early. When comparing tests plus CT scanning with tests alone, the quality of the evidence ranged from low to moderate due to imprecision caused by a low number of events and bias due to lack of blinding of people assessing the effects.

This review found that there are too few trials to determine whether testing for undiagnosed cancer in people with a first unprovoked VTE (DVT or PE) is effective in reducing cancer and VTE-related deaths and illness. Further good-quality and large-scale studies are required. 


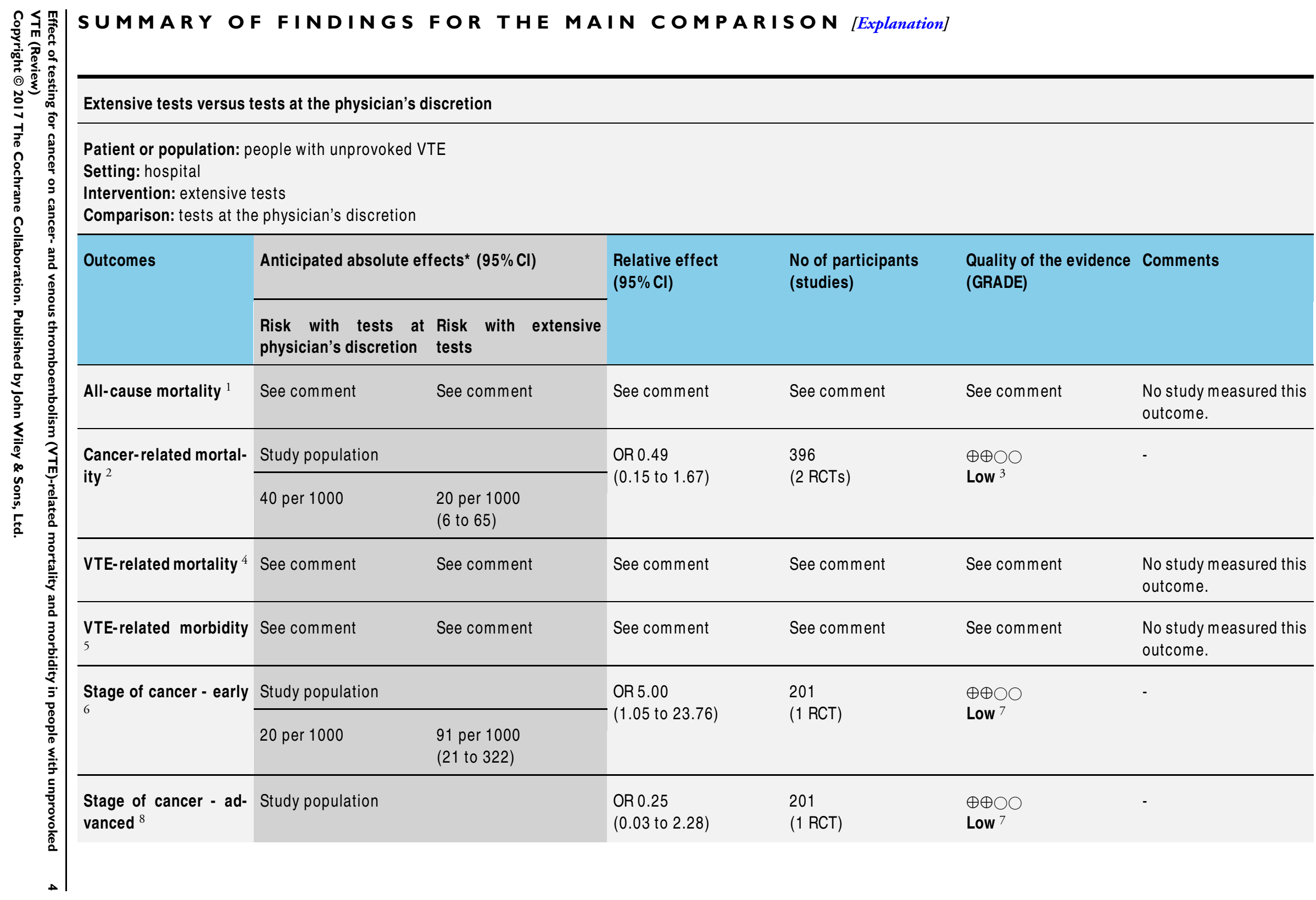




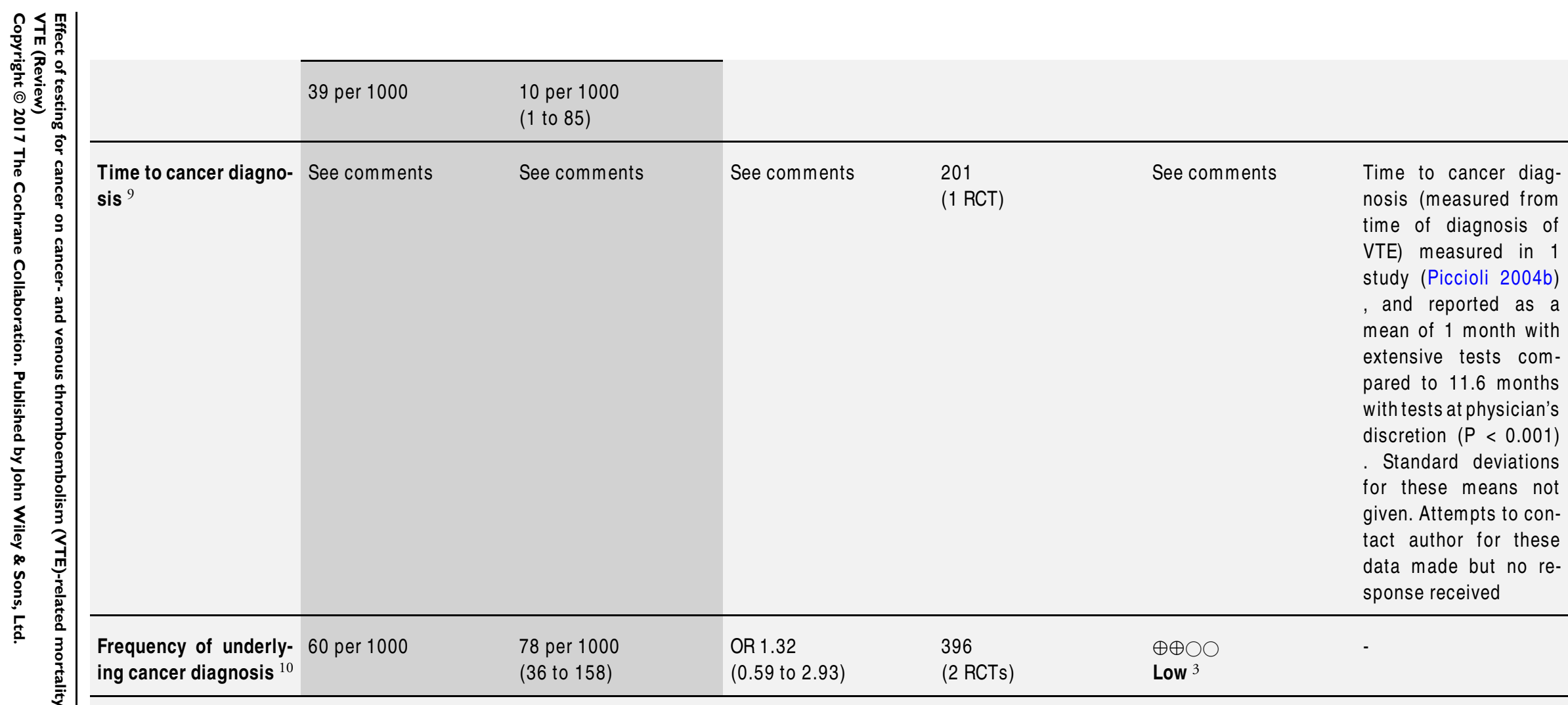

${ }^{*}$ The risk in the intervention group (and its $95 \%$ confidence interval) is based on the assumed risk in the comparison group and the relative effect of the intervention (and its $95 \% \mathrm{Cl})$.

Cl: confidence interval; OR: odds ratio; RCT: randomised controlled trial; VTE: venous thromboembolism.

\section{GRADE Working Group grades of evidence}

High quality: We are very confident that the true effect lies close to that of the estimate of the effect.

Moderate quality: We are moderately confident in the effect estimate: The true effect is likely to be close to the estimate of the effect, but there is a possibility that it is substantially different.

Low quality: Our confidence in the effect estimate is limited: The true effect may be substantially different from the estimate of the effect.

Very low quality: We have very little confidence in the effect estimate: The true effect is likely to be substantially different from the estimate of effect

${ }^{1}$ Death due to any cause. 
${ }^{2}$ Defined as death due to malignant disease itself, or death due to complications of treatments or procedures to diagnose or treat cancer.

${ }^{3}$ Risk of bias was high in two included studies (Piccioli 2004b; Prandoni 2016). Piccioli 2004b terminated early after inclusion of only 201 participants after 5 years for several reasons. First, only five of more than 40 potential participating centres could contribute participants to study. Second, some medical ethics committees rejected the protocol because of absence of screening for occult cancer in the control group, other centres could not start because the proposed extensive screening was judged unethical. Finally, identification of cancer at an apparent early stage in extensive screening group led to an increasing tendency among physicians in participating hospitals to initiate screening for cancer in control participants. Prandoni 2016 study terminated early due to low recruitment rate and failure to show an appreciable advantage of CT-based strategy over control strategy for detection of cancer.

${ }^{4}$ Fatal pulmonary embolism (PE). PE diagnosed "on the basis of a lung scan indicating a high probability of its presence, as indicated by the presence of new or enlarged areas of segmental perfusion defects with ventilation-perfusion mismatch; an abnormal perfusion scan with documentation of new or recurrent deep vein thrombosis (DVT); the presence of nonenhancing filling defects in the central pulmonary vasculature on helical computed tomography; a finding of intraluminal filling defects on pulmonary angiography; or evidence of fresh PE at autopsy" (Lee 2003b). Fatal PE including probable fatal PE and unexplained sudden death used if reported, as defined by individual studies.

${ }^{5}$ Frequency of recurrent VTE. Recurrent PE or DVT diagnosed if a previously compressible proximal venous segment or segments could no longer be compressed on ultrasonography or if there were constant intraluminal filling defects in two or more projections on venography. Unequivocal extension of the thrombus required for diagnosis of recurrence if results abnormal on previous testing (Lee 2003b)

${ }^{6}$ Early-stage malignancies, defined as T1 or T2 without locoregional or distant metastases (NO M0).

${ }^{7}$ Quality of evidence downgraded for imprecision due to low number of events. Evidence downgraded further as risk of bias high in Piccioli 2004b. Study terminated early after inclusion of only 201 participants after five years for several reasons. First only five of more than 40 potential participating centres could contribute participants to study. Second, some medical ethics committees rejected the protocol because of absence of screening for occult cancer in the control group, other centres could not start because the proposed extensive screening was judged unethical. Finally, identification of cancer at an apparent early stage in extensive screening group led to an increasing tendency among physicians in participating hospitals to initiate screening for cancer in control participants.

${ }^{8}$ Advanced-stage malignancies, defined as T3 with locoregional or distant metastases (N1 or M1).

Time to cancer diagnosis, as defined in included studies.

${ }^{10}$ Frequency of an underlying cancer diagnosis (i.e. number of times cancer diagnosed through screening following an unprovoked VTE as defined in included studies) at time of VTE presentation and overall over follow-up period. 


\section{B A C K G R O U N D}

\section{Description of the condition}

Venous thromboembolism (VTE) is the collective term for the clinical conditions deep vein thrombosis (DVT) and pulmonary embolism (PE). DVT is the formation of a blood clot (thrombus) in a deep vein, predominantly in the legs. Symptoms include pain, tenderness, erythema and swelling of the affected leg. PE occurs when part or all the thrombus breaks off (embolises) and travels up to the lungs blocking the pulmonary arteries. Symptoms of PE include breathlessness and chest pain (Blann 2006).

Guidelines published by the UK National Institute for Health and Care Excellence (NICE) recommend that people with a suspected VTE should be risk stratified using various diagnostic investigations. Anticoagulant therapy with low molecular weight heparin (LMWH) should be administered in the interim. People with confirmed VTE should receive LMWH or fondaparinux for at least the initial five days and be started on a vitamin $\mathrm{K}$ antagonist. The LMWH should be stopped when the international normalised ratio has been above 2 for at least 24 hours. Vitamin K antagonists should be continued for at least three months. In people with an unprovoked VTE, consideration should be given to extending anticoagulation beyond three months. However, people with cancerassociated VTE should be treated with LMWH from the initial diagnosis for a period of six months, and considered for continuation of anticoagulation with either LMWH or a vitamin K antagonist based on the status of the underlying cancer and risks of anticoagulation (NICE 2012). Direct oral anticoagulants (DOACs) such as rivaroxaban have been used for the initial treatment and prevention of recurrent VTE. Two systematic reviews have shown that DOACs may be as safe and effective as conventional anticoagulation for the prevention of recurrent VTE in people with cancer but, direct comparisons to the current standard of care with LMWH are limited (Carrier 2014; Vedovati 2015).

The difference in management of people with a cancer-associated VTE is due to their significantly higher risk of VTE recurrence, which is estimated to be three times higher than in people with VTE in the absence of cancer (Levitan 1999). Furthermore, people with cancer and an associated VTE have a poorer overall prognosis compared to people without a VTE (Sorensen 2000).

A proportion of people with VTE have no underlying or immediately apparent cause and the VTE is referred to as unprovoked. Unprovoked VTE can suggest underlying malignancies such as cancer of the blood, kidney, ovary, pancreas, stomach and lung (Bick 1978; Kakkar 2003; Lee 2003a; Prandoni 1997; White 2005). Results from one Swedish prospective cohort study of almost 62,000 participants determined that the standardised incidence ratio of a cancer diagnosis within the first two years of an unprovoked VTE was 4.4 (Baron 1998), and there was an overall absolute incidence of cancer of $11 \%$ (NICE 2012). One study of 339 participants with a first episode of an unprovoked VTE determined that the risk ratio (RR) of cancer-related mortality at two years was 0.52 ( $95 \%$ confidence interval (CI) 0.10 to 2.75 ) in people undergoing intensive investigations compared to routine tests, while the RR for early-stage cancer detection was 3.21 (95\% CI 0.88 to 11.79) (Piccioli 2004a).

Therefore, people who present with an apparent unprovoked VTE have a significant underlying risk of malignancy or cancer-associated VTE, with significant implications for the management of the VTE itself (three months' vitamin $\mathrm{K}$ antagonist versus six months' LMWH), the prognosis related to risk of VTE recurrence and the precipitating cancer. Detection of cancer at an earlier stage enables more effective treatment. This has raised the question of whether people with an unprovoked VTE should be investigated for an underlying cancer. Some authors have referred to this as 'screening for cancer' although this is somewhat misleading as screening refers to the investigation of asymptomatic people. Instead, people with VTE are better regarded as presenting with symptoms suggestive of an underlying cancer and the aim of investigations is to refine the diagnosis of VTE based on the underlying cause, so that the person may receive a more accurate diagnosis and appropriate treatment for their VTE. In this context, VTE represents a symptom rather than a diagnosis per se. So, to what extent should people with an unprovoked VTE be investigated for a potential underlying cancer?

\section{Description of the intervention}

The NICE guidelines on VTE disease recommend that all people presenting with a first episode of unprovoked VTE (DVT or PE) should undergo a history and physical examination directed to detecting an underlying malignancy, and further tests guided by the history and examination including blood tests (complete blood count, serum calcium and liver function tests), urinalysis and chest X-ray (NICE 2012). If none of these initial investigations suggest signs and symptoms of cancer then further tests including abdomino-pelvic computed tomography (CT) scan (and a mammogram for women) are recommended in people aged over 40 years (NICE 2012). It is the value of these additional tests which is the subject of this review.

\section{How the intervention might work}

The interventions for detecting an underlying cancer will enable a diagnosis of cancer-associated VTE to be made. This will enable the person to receive appropriate anticoagulation with LMWH versus vitamin $\mathrm{K}$ antagonist, for six versus three months respectively, and for the underlying cancer to be treated promptly without the need for additional symptoms to emerge before it is diagnosed. One study has shown that the combination of tests recommended by NICE detects cancer in approximately $10 \%$ of people with a first episode of unprovoked VTE and with no prior cancer 
diagnosis (Piccioli 2004a). However, tests for cancer also have the potential for harm, from the pain and inconvenience of blood tests to more serious complications due to radiation exposure from Xrays and CT scans.

\section{Why it is important to do this review}

The pharmacological management of VTE in people with and without cancer is considerably different, both in terms of choice of agent and duration of anticoagulation. Therefore, an appropriate cancer diagnosis would ensure that people received the optimal form and duration of anticoagulation, which, in turn, could reduce the overall population VTE recurrence rate and associated morbidity. Establishing whether a person with an apparently unprovoked VTE has an underlying cancer is important since this may lead to cancer diagnosis at an earlier, potentially curative stage, avoiding the risk of cancer progression while waiting for additional symptoms. This may, in turn, lead to improvements in cancerrelated mortality and morbidity. To date, no systematic review has been conducted to measure the effectiveness of testing for cancer in people with an unprovoked VTE. This review provides evidence as to whether such tests for underlying cancer, followed by appropriate alteration in the management or treatment of VTE, or both, are effective in reducing morbidity (VTE recurrence) and mortality (VTE- and cancer-associated).

\section{O B J E C T I VES}

To determine whether testing for undiagnosed cancer in people with a first episode of unprovoked VTE (DVT of the lower limb or PE) is effective in reducing cancer and VTE-related mortality and morbidity and to determine which tests for cancer are best at identifying treatable cancers early.

The detailed objectives are as follows:

to determine whether testing for undiagnosed cancer in people with a first episode of unprovoked VTE (DVT of the lower limb or $\mathrm{PE}$ ) is effective in reducing cancer mortality and morbidity (cancer morbidity being the need for cancer treatment and effects producing reduced quality of life);

to determine whether testing for undiagnosed cancer in people with a first episode of unprovoked VTE (DVT or PE) is effective in reducing VTE-related mortality and morbidity;

to determine which tests for cancer are best at identifying treatable cancers early.

\section{MET HODS}

\section{Criteria for considering studies for this review}

\section{Types of studies}

Randomised and quasi-randomised trials (where a method of allocation was used that was not truly random) in which people with an unprovoked VTE were allocated to receive different tests for cancer or tests as per physician discretion. We looked primarily at randomisation within three months of a VTE, as used in the SOMIT trial (Piccioli 2004a). However, we also included trials where randomisation occurred at different time points as a subgroup analysis. We included published studies and studies in progress if preliminary results were available. Non-English language studies were also eligible for inclusion in the review.

\section{Types of participants}

People with a first episode of unprovoked VTE (DVT of the lower limb or PE) with no pre-existing or clinically apparent cancer diagnosis.

\section{Types of interventions}

Tests for cancer (e.g. complete blood count, serum calcium, liver function test, urinalysis, chest X-ray, all forms of CT imaging, mammogram, tumour markers, sputum cytology, ultrasonography, positron emission tomography (PET) scan and colonoscopy) versus no tests for cancer or alternative tests, followed by appropriate treatment for cancer or change in VTE treatment regimen, or both. Studies where these tests were routinely used in all groups were not included. However, we included any study that focused on some other aspect of care than cancer only if the test for cancer was the subject of randomisation.

\section{Types of outcome measures}

\section{Primary outcomes}

1. All-cause mortality (death due to any cause).

2. Cancer-related mortality (defined as death due to a malignant disease itself, or death due to complications of treatments or procedures to diagnose or treat the cancer).

3. VTE-related mortality (fatal PE). PE diagnosed "on the basis of a lung scan indicating a high probability of its presence, as indicated by the presence of new or enlarged areas of segmental perfusion defects with ventilation-perfusion mismatch; an abnormal perfusion scan with documentation of new or recurrent DVT; the presence of non-enhancing filling defects in the central pulmonary vasculature on helical CT; a finding of intraluminal filling defects on pulmonary angiography; or evidence of fresh PE at autopsy" (Lee 2003b). Fatal PE including probable fatal PE and unexplained sudden death were used if reported, as defined by individual studies.

Effect of testing for cancer on cancer- and venous thromboembolism (VTE)-related mortality and morbidity in people with unprovoked 


\section{Secondary outcomes}

1. VTE-related morbidity (e.g. frequency of recurrent VTE).

Recurrent PE or DVT was diagnosed if a previously compressible proximal venous segment or segments could no longer be compressed on ultrasonography or if there were constant intraluminal filling defects in two or more projections on venography. Unequivocal extension of the thrombus required for the diagnosis of recurrence if the results were abnormal on previous testing (Lee 2003b).

2. Complications of anticoagulation (e.g. warfarin- versus LMWH-associated bleeding). We reported on major bleeding and minor bleeding if reported in the included studies. Major bleeding included bleeding associated with death, bleeding at a critical site (intracranial, intraspinal, intraocular, retroperitoneal or pericardial area), bleeding resulting in a need for a transfusion of at least two units of blood or bleeding leading to a drop in haemoglobin of at least $2.0 \mathrm{~g} / \mathrm{dL}$ (Lee 2003b). Minor bleeding included any other bleeding.

3. Adverse effects of cancer tests (e.g. radiation exposure, bleeding, as defined in included studies).

4. Characteristics of diagnosed cancer (e.g. primary tumour, stage, localised (curable) versus advanced (palliative) as defined in included studies).

5. Time to cancer diagnosis, as defined in included studies.

6. Frequency of an underlying cancer diagnosis (i.e. the number of times cancer was diagnosed through screening following an unprovoked VTE as defined in included studies) at the time of VTE presentation and overall over the follow-up period.

7. Participant satisfaction (if assessed in individual studies, we reported results descriptively using the definition provided by the trialists).

8. Quality of life.

\section{Search methods for identification of studies}

There was no restriction on date or language of publication.

\section{Electronic searches}

For this update the Cochrane Vascular Information Specialist (CIS) searched the Specialised Register (16 February 2017). In addition, the CIS searched the Cochrane Register of Studies (CRS; www.metaxis.com/CRSWeb/Index.asp; CENTRAL 2017, Issue 1). See Appendix 1 for details of the search strategy used to search the CRS. The Specialised Register is maintained by the CIS and is constructed from weekly electronic searches of MEDLINE, Embase, CINAHL and AMED, and through handsearching relevant journals. The full list of the databases, journals and conference proceedings which have been searched, as well as the search strategies used are described in the Specialised Register sec- tion of the Cochrane Vascular module in the Cochrane Library ( www.cochranelibrary.com).

In addition, the CIS searched the following trial databases (16 February 2017) for details of ongoing and unpublished studies. See Appendix 2.

1. World Health Organization International Clinical Trials Registry Platform (apps.who.int/trialsearch/);

2. ClinicalTrials.gov (clinicaltrials.gov/);

3. ISRCTN registry (www.isrctn.com/).

\section{Searching other resources}

We searched the reference lists of relevant articles retrieved by the electronic searches for additional citations. Furthermore, we searched the conference proceeding abstracts of the following societies:

1. International Society for Thrombosis and Haemostasis (ISTH) (2003 to 2016);

2. American Society for Hematology (ASH) (2004 to 2016).

\section{Data collection and analysis}

\section{Selection of studies}

Two review authors (LR, SEY) independently used the selection criteria to identify trials for inclusion. We resolved any disagreements by discussion.

\section{Data extraction and management}

Two review authors (LR, SEY) independently extracted the data and recorded information about the trial design, VTE definition and investigations to confirm diagnosis, baseline characteristics of participants and tests for cancer. All-cause mortality, cancerrelated mortality and VTE-related mortality data were recorded as the primary outcome measures. Information on VTE-related morbidity (e.g. frequency of recurrent VTE), complications of anticoagulation (e.g. warfarin- versus LMWH-associated bleeding), adverse effects of cancer tests (e.g. radiation exposure, bleeding), characteristics of diagnosed cancer (e.g. primary tumour, stage, localised (curable) versus advanced (palliative)), time to cancer diagnosis, frequency of an underlying cancer diagnosis and participant satisfaction was collected in accordance with the secondary outcome measures. Where more than one publication of one study existed, reports were grouped together and the most recent or most complete data set were used. We contacted authors of included studies for further information if clarification was required. We resolved any disagreements in data extraction and management by discussion. 


\section{Assessment of risk of bias in included studies}

Two review authors (LR, SEY) independently used the Cochrane tool to assess the risk of bias for each of the included studies (Higgins 2011). The tool provides a protocol for judgements on sequence generation, allocation methods, blinding, incomplete outcome data, selective outcome reporting and any other relevant biases. We judged each of these domains at high, low or unclear risk of bias according to Higgins 2011 and provided support for each judgement. The conclusions are presented in a 'Risk of bias' table. Any disagreements were resolved by discussion.

\section{Measures of treatment effect}

We planned to base the analysis on intention-to-treat data from the individual clinical trials. The majority of outcomes were binary measures (mortality, morbidity, complications, adverse effects, characteristics of diagnosed cancer, frequency of an underlying cancer diagnosis). For these outcomes, we computed odds ratios (ORs) using a random-effects model and calculated the $95 \%$ $\mathrm{CI}$ of the effect sizes. For time to cancer diagnosis, we aimed to compute hazard ratios (HR), while for participant satisfaction, we planned to report results descriptively (Deeks 2011).

\section{Unit of analysis issues}

The unit of analysis within each trial was the individual participant.

\section{Dealing with missing data}

We sought information about dropouts, withdrawals and other missing data and, if not reported, we contacted the study authors.

\section{Assessment of heterogeneity}

We assessed heterogeneity between the pooled studies by visual examination of the forest plot to check for overlapping CIs, and used the $\mathrm{Chi}^{2}$ test for homogeneity with a $10 \%$ level of significance. We used the $\mathrm{I}^{2}$ statistic to measure the degree of inconsistency between the studies. An $\mathrm{I}^{2}$ result of over 50\% may represent moderate to substantial heterogeneity (Deeks 2011).

\section{Assessment of reporting biases}

We planned to assess reporting biases such as publication bias using funnel plots when there were more than 10 studies in the metaanalyses (Sterne 2011). However, as there were only four studies in the review it was not possible to test for funnel plot asymmetry.

\section{Data synthesis}

The review authors independently extracted the data. One review author (LR) entered the data into Review Manager 5 (RevMan
2014). A second review author (SEY) cross-checked data entry and resolved any discrepancies by consulting the source publication. We used a random-effects model for meta-analysis of the data. We planned to stratify analyses according to the individual cancer test being assessed and the combination of tests as used in the SOMIT trial (Piccioli 2004a).

\section{Subgroup analysis and investigation of heterogeneity}

Where possible, we planned to analyse clinically relevant subgroups based on the following:

1. DVT or PE at time of randomisation;

2. cancer site;

3. treatment post-investigation with vitamin $\mathrm{K}$ antagonist or LMWH;

4. duration of anticoagulation (e.g. three or six months);

5. age and gender of participants (comparing those in age and gender groups for national screening programmes to those not in these age and gender groups);

6. time of randomisation after VTE diagnosis (within three months compared with after three months).

However, due to lack of data in the studies, it was not possible to perform subgroup analysis.

\section{Sensitivity analysis}

We planned to conduct a sensitivity analysis by excluding studies at high risk of bias to measure the effect on the results.

\section{'Summary of findings' table}

We presented the main findings of the review results concerning the quality of evidence, the magnitude of effect of the interventions examined and the sum of available data for all outcomes of this review (Types of outcome measures) in a 'Summary of findings' table, according to the GRADE principles as described by Higgins 2011 and Atkins 2004. We calculated assumed control intervention risks from the mean number of events in the control groups of the selected studies for each outcome. We used the GRADEprofiler (GRADEpro) software to assist in the preparation of the 'Summary of findings' table (www.guidelinedevelopment.org).

\section{RES U L T S}

\section{Description of studies}

\section{Results of the search}

See Figure 1.

Effect of testing for cancer on cancer- and venous thromboembolism (VTE)-related mortality and morbidity in people with unprovoked 
Figure I. Study flow diagram.

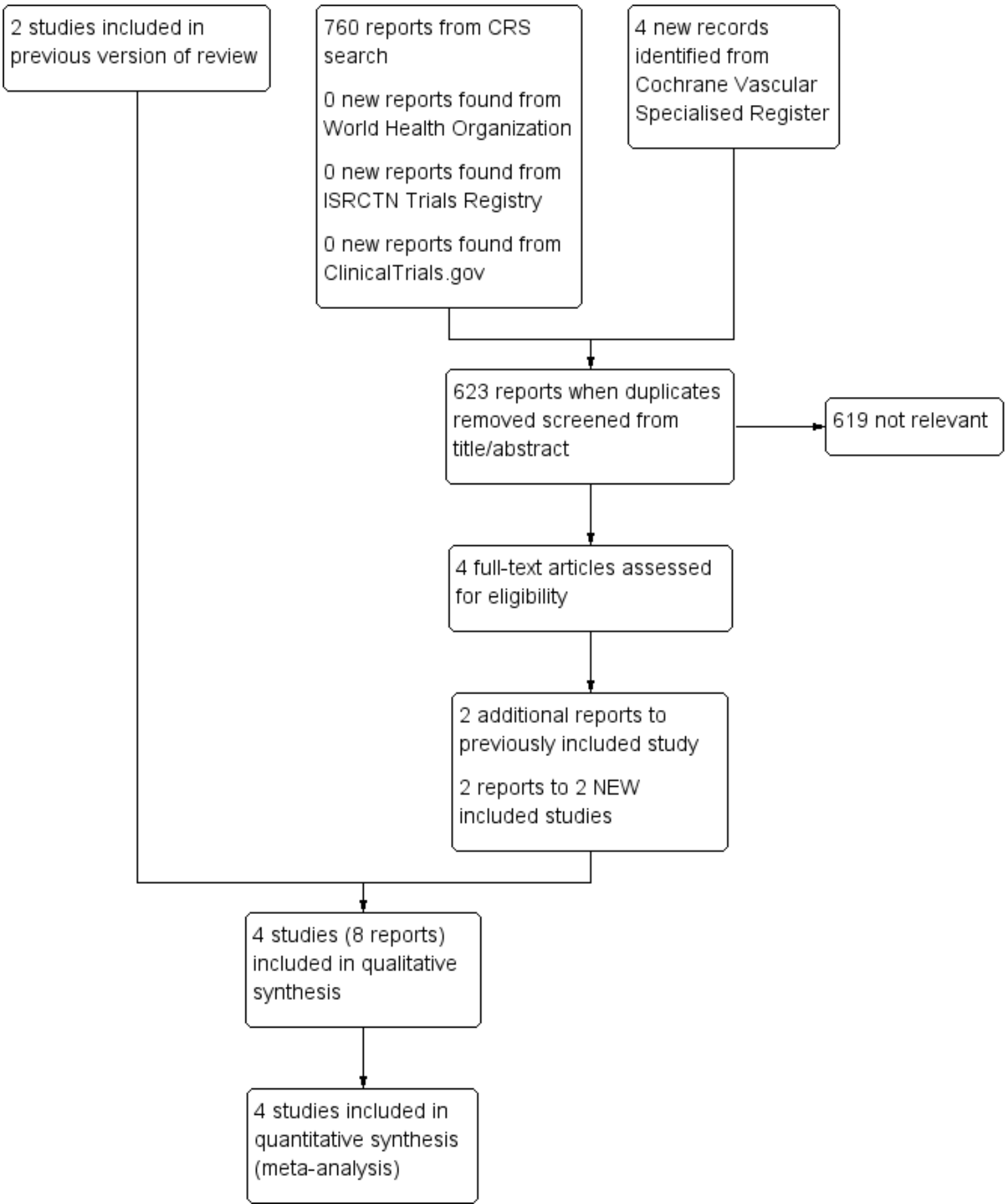

Effect of testing for cancer on cancer- and venous thromboembolism (VTE)-related mortality and morbidity in people with unprovoked I I VTE (Review)

Copyright @ 2017 The Cochrane Collaboration. Published by John Wiley \& Sons, Ltd. 


\section{Included studies}

This updated search identified two further studies (Carrier 2015; Robin 2016) making a total of four included studies (Carrier 2015; Piccioli 2004b; Prandoni 2016; Robin 2016).

See Characteristics of included studies table.

The first study was a randomised multicentre study of 201 apparently cancer-free people with acute unprovoked VTE (Piccioli 2004b). Extensive investigations for occult malignant disease were compared with testing at the physician's discretion. Ninety-nine participants were randomised to the extensive screening group and 102 were randomised to the control group. Participants in the extensive investigations group were offered ultrasound and CT scans of the abdomen and pelvis, double contrast barium swallowing, colonoscopy or sigmoidoscopy followed by a barium enema, haemoccult test, sputum cytology and tumour markers including carcinoembryonic antigen (CEA), alpha-fetoprotein $(\alpha-\mathrm{FP})$ and CA125. Women also underwent mammography and Papanicolaou (Pap) smears while men had transabdominal ultrasound of the prostate and a total prostate-specific antigen (PSA) test. All tests were completed within a four-week period from the diagnosis of VTE. Participants in the control group were investigated at the physician's discretion. If the investigations suggested the presence of a malignant process, further investigations were performed according to current standards. Participants were followed up at 3, 12 and 24 months following the diagnosis of VTE. The primary outcome was cancer-related morbidity, defined as death due to a malignant disease itself, or death due to complications of diagnostic or surgical procedures performed to diagnose or treat cancer. A secondary outcome of this study consisted of the cluster of cancer-related mortality and documented residual malignancy or recurrent malignancy at 24 months. The authors also measured the frequency of an underlying cancer diagnosis including type and stage as well as mean time to cancer diagnosis.

The second study was a randomised study in which 195 participants with a first episode of unprovoked VTE were randomised to extensive investigations (98 participants) or a discretionary diagnostic approach excluding CT scans (97 participants) (Prandoni 2016). Extensive investigations comprised a mandatory CT scan of the thorax, abdomen and pelvis together with faecal haemoccult testing or any test at physician's discretion according to good clinical practice. Participants allocated to the discretionary diagnostic approach or personalised strategy underwent additional testing based on physicians' judgements and participants' preferences, including a 'no-further testing' option. Participants were followed at 3, 6, 12 and 24 months to document the incidence of newly discovered cancer and cancer-related mortality. The primary outcomes were cancer-related mortality (defined as death due to malignancy, or death due to the complications of the diagnostic or surgical procedures performed to diagnose or treat cancer) and incidence of newly discovered cancer. The secondary outcomes were cancer stage, using the tumours-nodes-metastases classification, at which tumours were diagnosed in the two study groups and the incidence of cancer-related mortality in the two randomisation groups,

The third study was an open-label randomised study in which 854 participants with a first episode of unprovoked VTE were randomised to limited occult-cancer screening plus CT scanning of the abdomen and pelvis (423 participants) or limited occult-cancer screening alone (431 participants) (Carrier 2015). The limited occult-cancer screening comprised complete history and physical examination, measurement of complete blood counts and serum electrolyte and creatinine levels, liver-function testing and chest radiography. Sex-specific screening was conducted if it had not been performed in the previous year. A breast examination, mammography, or both were performed in women over 50 years of age and Pap testing and a pelvic examination were performed in women 18 to 70 years of age who had ever been sexually active. A prostate examination, PSA test, or both were performed in men over 40 years of age. The additional CT investigations comprised a virtual colonoscopy and gastroscopy, biphasic enhanced CT of the liver, parenchymal pancreatography and uniphasic enhanced CT of the distended bladder. Participants were followed up for one year to document the incidence of newly diagnosed cancer, type of cancer diagnosed, one-year cancer-related mortality, oneyear overall mortality, time to cancer diagnosis and incidence of recurrent VTE.

The fourth study was an open-label randomised study in which 394 participants with a first episode of unprovoked VTE were randomised to a limited screening strategy (197 participants) or a screening strategy consisting of the limited strategy plus an 18-fluorodeoxyglucose $\left({ }^{18} \mathrm{~F}\right.$-FDG) PET/CT scan of the chest, abdomen and pelvis (197 participants) (Robin 2016). The limited screening comprised medical history taking, physical examination, routine laboratory tests (including complete blood count, erythrocyte sedimentation rate or C-reactive protein, aminotransferases, alkaline phosphatase and calcium), chest radiograph, recommended agespecific and sex-specific cancer screening tests (i.e. PSA in men older than 50 years, mammography in women older than 50 years and Pap smear in all women). Participants were followed up for two years to determine the proportion of people with a cancer diagnosis in each group after the initial screening assessment.

\section{Excluded studies}

There were no studies excluded from the review. Studies that were not randomised controlled trials were deemed not relevant and therefore not listed as an excluded study.

Effect of testing for cancer on cancer- and venous thromboembolism (VTE)-related mortality and morbidity in people with unprovoked 


\section{Ongoing studies}

There were no ongoing studies.

\section{Risk of bias in included studies}

See Figure 2 and Figure 3.

Figure 2. Risk of bias graph: review authors' judgements about each risk of bias item presented as percentages across all included studies.

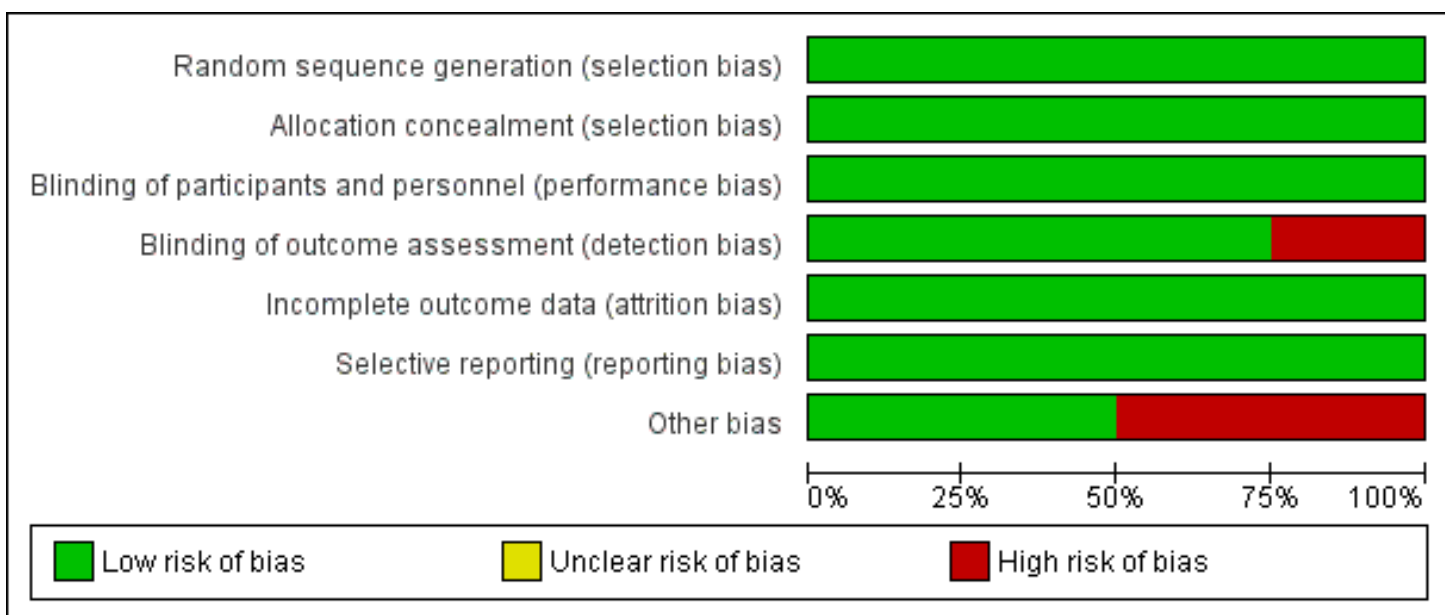

Effect of testing for cancer on cancer- and venous thromboembolism (VTE)-related mortality and morbidity in people with unprovoked 
Figure 3. Risk of bias summary: review authors' judgements about each risk of bias item for each included study.

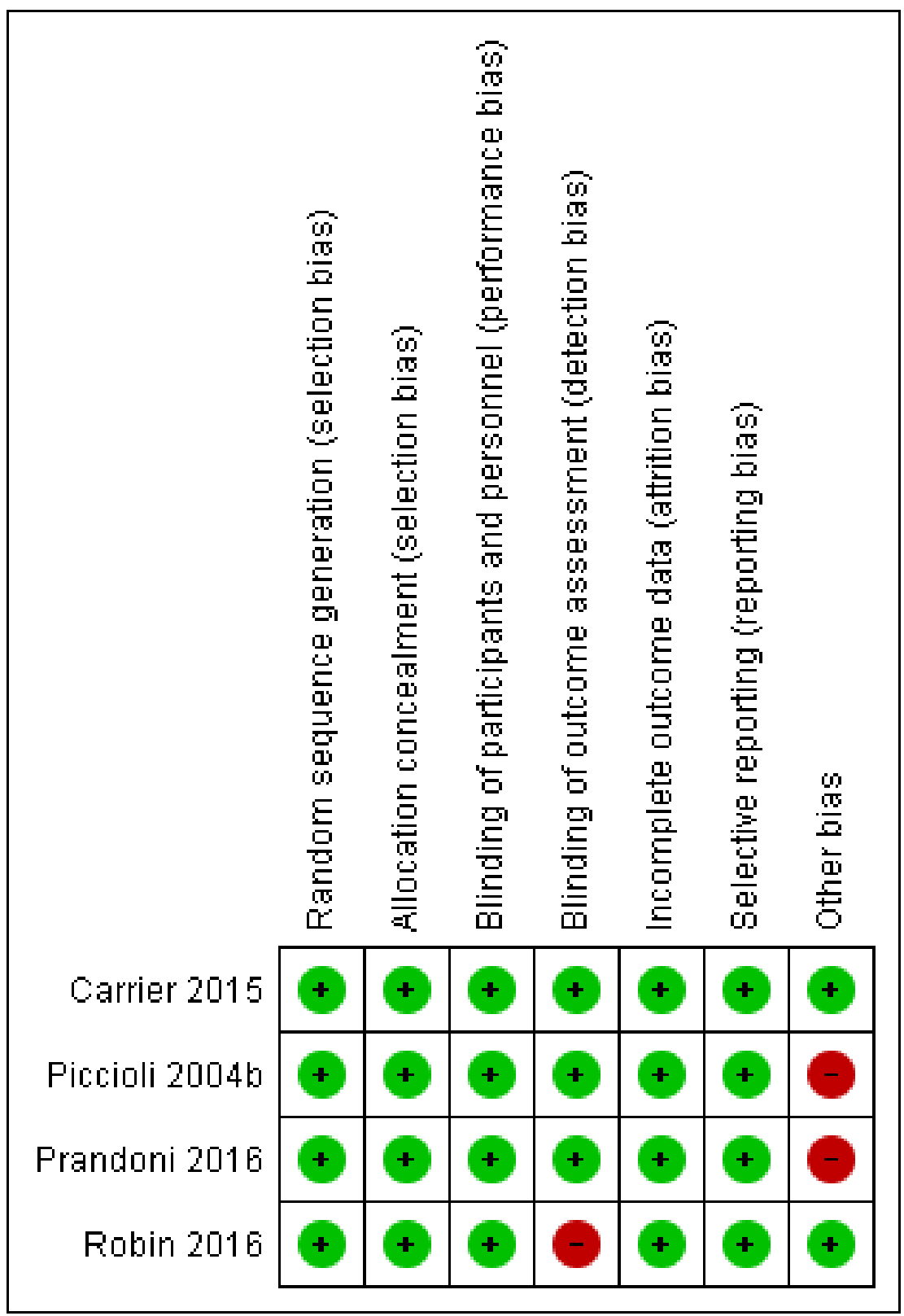

Effect of testing for cancer on cancer- and venous thromboembolism (VTE)-related mortality and morbidity in people with unprovoked 


\section{Allocation}

All four studies were randomised. Prandoni 2016 used envelopes. Piccioli $2004 \mathrm{~b}$ used a Zelen approach (participants are randomised to either the treatment or control group before giving informed consent), Carrier 2015 used random number tables and Robin 2016 used a computer random number generator. Therefore, these four studies were judged at low risk of selection bias. In terms of concealing the allocation of treatment, Piccioli 2004b performed randomisation centrally and Carrier 2015 and Robin 2016 used a central web-based randomisation system and, therefore, these three were judged at low risk of selection bias. The Prandoni 2016 study used serially numbered, opaque, sealed envelopes to conceal allocation and was, therefore, judged at low risk of selection bias too.

\section{Blinding}

As the study groups in all four trials were randomised to extensive screening or no further testing, it was impossible to blind participants and study personnel. However, we believe it was unlikely that the lack of blinding would have affected the outcome and, therefore, all studies were judged at low risk of performance bias. In Piccioli 2004b, the physician at the follow-up examination was unaware of the allocation of participants and, therefore, detection bias for outcome assessors was low. Similarly for Carrier 2015, a blinded adjudication committee reviewed all suspected outcome events and, therefore, the risk of detection bias was low. Robin 2016 did not blind outcome assessors to treatment allocation and was, therefore, judged at high risk of detection bias. In Prandoni 2016, investigators performing the follow-up visits were blinded to the participants' randomisation group and the study was, therefore, judged at low risk of detection bias.

\section{Incomplete outcome data}

The treatment groups in all four studies were well-balanced with respect to baseline characteristics, completion of the study protocol and discontinuation of treatment. Furthermore, all missing data were accounted for and reported. Therefore, all four studies were judged at low risk of attrition bias (Carrier 2015; Piccioli 2004b; Prandoni 2016; Robin 2016).

\section{Selective reporting}

All four studies clearly prespecified all primary and secondary outcomes and data on all outcomes were reported (low risk of reporting bias) (Carrier 2015; Piccioli 2004b; Prandoni 2016; Robin 2016).

\section{Other potential sources of bias}

Two studies were deemed at low risk (Carrier 2015; Robin 2016), and two studies were deemed to be at high risk of other bias (Piccioli 2004b; Prandoni 2016). The study by Piccioli 2004b was terminated early after the inclusion of only 201 participants after five years for several reasons. First, only five of the more than 40 potential participating centres could contribute participants to the study. Second, some medical ethics committees rejected the protocol because of the absence of screening for occult cancer in the control group, other centres could not start because the proposed extensive screening was judged to be unethical. Finally, the identification of cancer at an apparent early stage in the extensive screening group led to an increasing tendency among physicians in the participating hospitals to initiate screening for cancer in the control participants. The study by Prandoni 2016 was judged at high risk of bias as results of an interim analysis, scheduled after the inclusion of approximately half of the planned sample size, showed no appreciable advantage of the CT-based strategy over the control strategy for detection of occult cancers. In addition, there was a low recruitment rate, so the study promoters decided to terminate the study early.

\section{Effects of interventions}

See: Summary of findings for the main comparison Extensive tests versus tests at the physician's discretion; Summary of findings 2 Standard testing plus PET/CT scanning versus standard testing alone

\section{Extensive tests versus tests at the physician's discretion}

Two studies assessed the effect of testing for cancer versus clinically indicated tests only (Piccioli 2004b; Prandoni 2016).

Both studies measured the primary outcome cancer-related mortality. In Piccioli 2004b, 2/99 participants in the extensive testing group died of cancer compared to $4 / 102$ in the group who underwent tests at the physician's discretion (OR $0.51,95 \%$ CI 0.09 to 2.82). In Prandoni 2016, 2/98 participants who underwent extensive testing and 4/97 participants who underwent tests at the physician's discretion died of cancer (OR $0.48,95 \%$ CI 0.09 to 2.71). Meta-analysis showed an OR of 0.49 (95\% CI 0.15 to 1.67 ; low quality evidence) in favour of extensive testing, which did not reach statistical significance $(\mathrm{P}=0.26)$ (Analysis 1.1).

However, neither Piccioli 2004b nor Prandoni 2016 measured the review's other primary outcomes of all-cause mortality and VTErelated mortality, or the secondary outcomes VTE-related morbidity, complications of anticoagulation, adverse effects of cancer tests, participant satisfaction and quality of life.

Piccioli 2004b looked at the location of the malignancy and found no clear difference in the incidence of any particular cancer be-

Effect of testing for cancer on cancer- and venous thromboembolism (VTE)-related mortality and morbidity in people with unprovoked 
tween participants who underwent extensive tests and participants who were tested at the physician's discretion (lung: OR 2.08, 95\% CI 0.19 to 23.34; bladder: OR 2.08, $95 \%$ CI 0.19 to 23.34; stomach: OR 1.03, 95\% CI 0.06 to 16.71 ; kidney: OR 3.12, 95\% CI 0.13 to 77.55 ; adrenal gland: OR $3.12,95 \%$ CI 0.13 to 77.55 ; liver: OR 3.12, 95\% CI 0.13 to 77.55 ; uterus: OR 3.12, 95\% CI 0.13 to 77.55 ; breast: OR $1.03,95 \%$ CI 0.06 to 16.71 ; ovary: OR 3.12, 95\% CI 0.13 to 77.55 ; colon: OR $0.51,95 \%$ CI 0.05 to 5.72 ; prostate: OR $0.51,95 \%$ CI 0.05 to 5.72 ; pancreas: OR $0.20,95 \%$ CI 0.01 to 4.26 ) (Analysis 1.2 ).

Piccioli $2004 \mathrm{~b}$ compared the characteristics of the diagnosed cancer by assessing the proportion of early-stage malignancies, defined as T1 or T2 without locoregional or distant metastases (N0 M0). Overall, malignancies were less advanced in participants who had undergone extensive testing. In total, 9/13 participants diagnosed with cancer in the tested group had a T1- or T2-stage malignancy without locoregional or distant metastases compared to $2 / 10$ participants diagnosed with cancer in the control group (OR 5.00, $95 \%$ CI 1.05 to $23.76 ; \mathrm{P}=0.04$; low quality evidence). There was no difference in detection of advanced stages between groups: one participant in the tested group had stage T3 compared with four participants in the control group (OR 0.25, 95\% CI 0.03 to 2.28; $\mathrm{P}=0.22$; low quality evidence) (Analysis 1.3 ).

One study measured time to cancer diagnosis (measured from the time of diagnosis of VTE) (Piccioli 2004b), reported as a mean of one month in tested participants compared to 11.6 months in participants who were tested at the physician's discretion ( $\mathrm{P}$ $<0.001)$. Standard deviations for the means were not given. We attempted to contact the author for these data but received no response.

Both studies measured the frequency of an underlying cancer diagnosis. Piccioli $2004 \mathrm{~b}$ detected underlying cancer in 13/99 participants who underwent extensive testing, whereas it became symptomatic in 10/102 control participants (OR 1.39, 95\% CI 0.58 to 3.34). Prandoni 2016 detected cancer in $2 / 98$ participants who had further tests and it became apparent in 2/97 participants who were tested at the physician's discretion (OR 0.99, 95\% CI 0.14 to 7.17). The combined incidence of an underlying cancer diagnosis was $15 / 197$ in the tested group and 12/199 in the control group (OR 1.32, 95\% CI 0.59 to 2.93; low quality evidence) (Analysis 1.4). Therefore, after 24 months of follow-up, the incidence of cancer was no different in the tested and control groups.

\section{Standard testing plus PET/CT scanning versus standard testing alone}

Two studies assessed the effect of standard testing plus PET/ CT scanning versus standard testing alone (Carrier 2015; Robin 2016).

Both studies measured the primary outcome all-cause mortality.
In the standard testing plus CT scanning group, 11/620 participants died during follow-up compared to $9 / 628$ participants who received standard testing alone (OR 1.22, 95\% CI 0.49 to 3.04; moderate quality evidence) (Analysis 2.1).

Carrier 2015 and Robin 2016 also measured cancer-related mortality and reported an incidence of 6/620 participants with standard testing plus CT scanning compared to $11 / 628$ participants who received standard testing alone (OR $0.55,95 \%$ CI 0.20 to 1.52; moderate quality evidence) (Analysis 2.2).

The study by Carrier 2015 measured VTE-related morbidity. The incidence of recurrent VTE was 14/423 participants who underwent standard testing plus CT scanning compared to $14 / 431$ participants who had standard testing alone (OR 1.02, 95\% CI 0.48 to 2.17; moderate quality evidence) (Analysis 2.3).

Carrier 2015 and Robin 2016 also looked at the location of the malignancy and found no clear difference in the incidence of any particular cancer between the two groups (acute leukaemia: OR 1.62, $95 \%$ CI 0.20 to 13.22 ; gynaecological: OR 2.39, $95 \%$ CI 0.43 to 13.36 ; melanoma: OR $1.02,95 \%$ CI 0.06 to 16.34 ; colorectal: OR $0.43,95 \%$ CI 0.08 to 2.40 ; prostate: OR $2.52,95 \%$ CI 0.48 to 13.12 ; pancreatic: OR $4.81,95 \%$ CI 0.55 to 42.48 ; cholangiocarcinoma: OR $0.51,95 \%$ CI 0.05 to 5.63 ; lymphoma: OR $0.74,95 \%$ CI 0.09 to 5.83 ; breast: OR $0.20,95 \%$ CI 0.01 to 4.24; urological: OR $0.62,95 \%$ CI 0.03 to 12.32 ; liver: OR 0.33 , 95\% CI 0.01 to 8.19 ; head and neck: OR $3.02,95 \%$ CI 0.12 to 74.47; lung: OR 3.02, 95\% CI 0.12 to 74.47 ; unknown primary origin: OR $0.34,95 \%$ CI 0.01 to 8.34 ) (Analysis 2.4).

Robin 2016 also measured the stage of cancer. Early-stage cancer was detected in 7/197 participants who underwent standard testing plus CT scanning compared to $4 / 197$ participants who underwent standard testing alone (OR $1.78,95 \%$ CI 0.51 to 6.17 ; low quality evidence), while advanced-stage cancer was detected in two participants in each group (OR 1.00, 95\% CI 0.14 to 7.17; low quality evidence) (Analysis 2.5).

Time to cancer diagnosis was 4.0 months in the standard testing plus CT/PET group and 4.2 months in the standard testing group in one study $(\mathrm{P}=0.88)$ (Carrier 2015). However, standard deviations for these means were not given. We attempted to contact the author for these data but received no response. Robin 2016 did not measure time to cancer diagnosis.

Carrier 2015 and Robin 2016 measured the frequency of underlying cancer diagnosis. Underlying cancer was detected in 30/620 participants who underwent standard testing plus CT scanning compared to $18 / 628$ participants who underwent standard testing alone (OR 1.71, 95\% CI 0.91 to 3.20; moderate quality evidence) (Analysis 2.6).

The studies by Carrier 2015 and Robin 2016 did not measure the other review outcomes of VTE-related mortality, complications of anticoagulation, adverse effects of cancer tests, participant satisfaction or quality of life.

Effect of testing for cancer on cancer- and venous thromboembolism (VTE)-related mortality and morbidity in people with unprovoked 


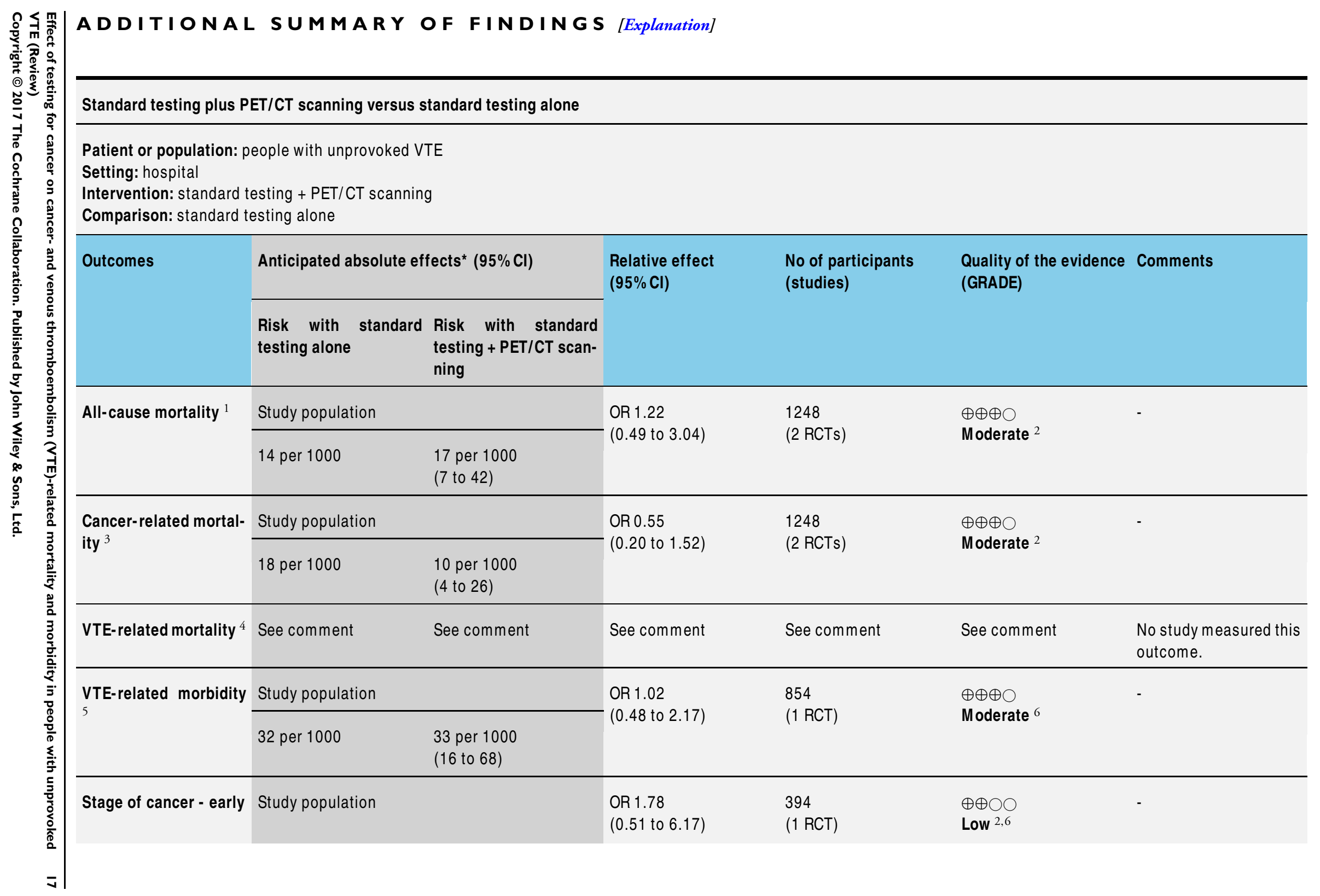




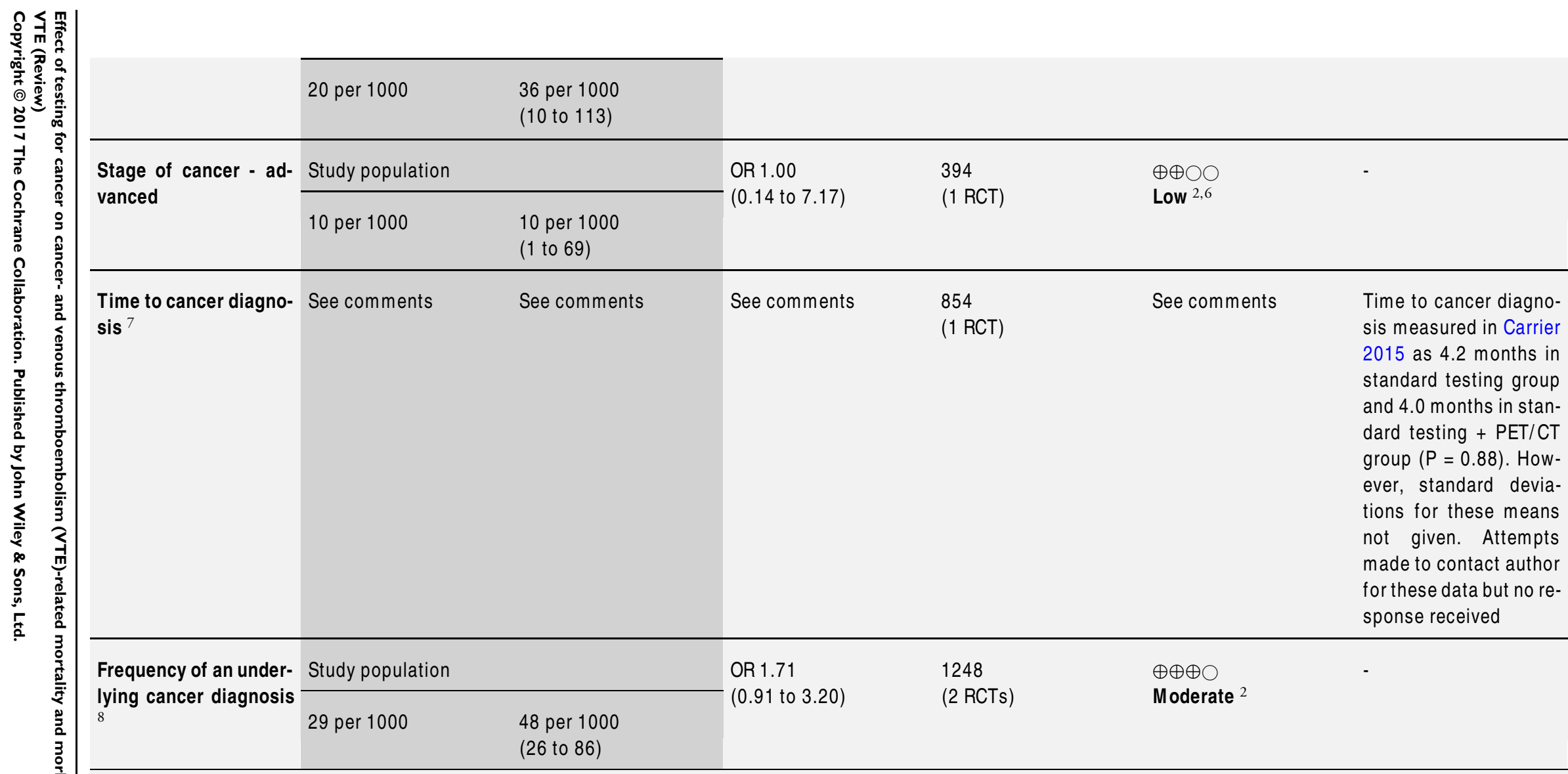

${ }^{*}$ The risk in the intervention group (and its $95 \%$ confidence interval) is based on the assumed risk in the comparison group and the relative effect of the intervention (and its $95 \% \mathrm{Cl})$.

Cl: confidence interval; OR: odds ratio; PET/CT: positron emission tomography/computed tomography; RCT: randomised controlled trial; VTE: venous thromboembolism.

\section{GRADE Working Group grades of evidence}

High quality: We are very confident that the true effect lies close to that of the estimate of the effect.

Moderate quality: We are moderately confident in the effect estimate: The true effect is likely to be close to the estimate of the effect, but there is a possibility that it is substantially different.

Low quality: Our confidence in the effect estimate is limited: The true effect may be substantially different from the estimate of the effect.

Very low quality: We have very little confidence in the effect estimate: The true effect is likely to be substantially different from the estimate of effect 


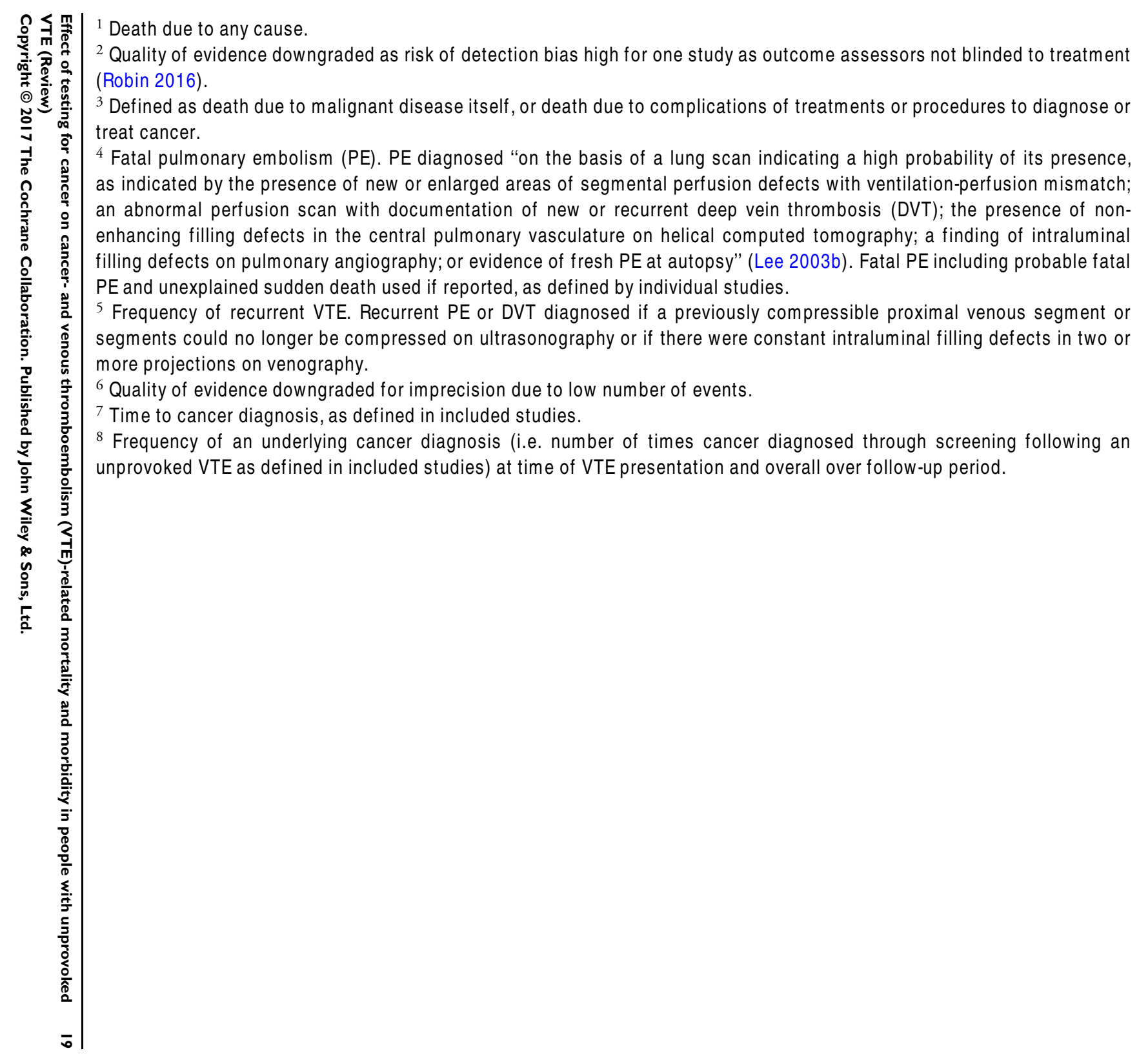




\section{DISCUSSION}

\section{Summary of main results}

Four studies fulfilled the eligibility criteria for inclusion in this review (Carrier 2015; Piccioli 2004b; Prandoni 2016; Robin 2016). In total, 1644 participants were studied. We found no studies that were potentially eligible but then excluded.

\section{Extensive tests versus tests at the physician's discretion}

Two studies compared the effectiveness of testing for cancer on cancer-related mortality in people with a first unprovoked VTE (Piccioli 2004b; Prandoni 2016). Piccioli 2004b performed an extensive list of tests while Prandoni 2016 carried out fewer tests. Pooled analysis showed that testing for cancer was consistent with either a benefit or no benefit on cancer-related mortality. Testing did not increase the frequency of an underlying cancer diagnosis. However, the time to cancer diagnosis was shorter in tested participants (mean: one month with extensive tests versus 11 months with tests at the physician's discretion). Furthermore, more people had a detection of early-stage cancer with extensive tests compared to people who were tested at the physician's discretion (Piccioli 2004b). However, standard deviations for the mean time to diagnosis were not reported and, therefore, it was impossible to independently test the statistical significance of this result. Neither study measured all-cause mortality, VTE-related morbidity and mortality, adverse effects of anticoagulation, adverse effects of cancer tests, participant satisfaction or quality of life.

\section{Standard testing plus PET/CT scanning versus standard testing alone}

Two studies compared limited screening plus PET/CT scanning of the abdomen and pelvis with limited screening alone in people with a first unprovoked VTE (Carrier 2015; Robin 2016). Standard testing plus PET/CT scanning was consistent with either a benefit or no benefit on all-cause mortality, cancer-related mortality and VTE-related morbidity. Extensive testing did not increase the frequency of an underlying cancer diagnosis. Furthermore, there was no clear difference in the incidence of particular types of cancer or the stage of cancer between the extensive and standard testing groups. One study measured time to cancer diagnosis but standard deviations for the mean time to diagnosis were not reported and, therefore, it was impossible to independently test the statistical significance of this result (Carrier 2015). Carrier 2015 and Robin 2016 did not measure VTE-related mortality, adverse effects of anticoagulation, adverse effects of cancer tests, participant satisfaction or quality of life.

\section{Overall completeness and applicability of evidence}

At present, there is limited evidence concerning whether testing for undiagnosed cancer in people with a first episode of unprovoked VTE (DVT or PE) is effective in reducing cancer- and VTE-related mortality and morbidity and which tests for cancer are most useful. Only four studies met the inclusion criteria for this review (Carrier 2015; Piccioli 2004b; Prandoni 2016; Robin 2016). While the losses to follow-up were equally balanced within each study, the number of participants in each study was relatively small and pooled analysis is based on 1644 participants. Furthermore, the four studies primarily looked at cancer-related mortality and incidence of cancer diagnosis as their main outcomes. Other outcomes of interest for this review, such as VTE-related mortality, adverse effects of anticoagulation, adverse effects of cancer tests and quality of life, were not studied and, therefore, remain unknown.

\section{Quality of the evidence}

One study included in the review was judged at low risk of bias (Carrier 2015). Piccioli 2004b was judged at high risk of bias as the study was terminated early for several reasons. First, only five of the more than 40 potential participating centres could contribute participants to the study. Second, some medical ethics committees rejected the protocol because of the absence of screening for occult cancer in the control group, other centres could not start because the proposed extensive screening was judged to be unethical. Finally, the identification of cancer at an apparent early stage in the extensive screening group led to an increasing tendency among physicians in the participating hospitals to initiate screening for cancer in the control participants. Prandoni 2016 was judged at low risk for all domains except other bias, where the risk was deemed to be high as, based on an interim analysis, the study was terminated early because of the low recruitment rate and of the failure to show an appreciable advantage of the CT-based strategy over the control strategy for detection of cancers. Robin 2016 was judged at low risk for all domains except detection bias, where the risk was deemed high due to lack of blinding of outcome assessors.

For the comparison extensive tests for cancer versus tests at the physician's discretion, the quality of the evidence for cancer-related mortality and frequency of an underlying cancer diagnosis was downgraded to low as there was a high risk of bias in both studies due to them both being terminated early. However, the outcome was direct and effect estimates were consistent and precise, as reflected in the narrow CIs around the ORs (Summary of findings for the main comparison). The quality of evidence for type of cancer are presented in a 'Summary of findings' table (Appendix 3). For type of cancer, the evidence was downgraded to low as there was imprecision due to low number of events combined with the

Effect of testing for cancer on cancer- and venous thromboembolism (VTE)-related mortality and morbidity in people with unprovoked 20 VTE (Review)

Copyright $\odot 2017$ The Cochrane Collaboration. Published by John Wiley \& Sons, Ltd. 
study being terminated early.

For the comparison standard testing plus PET/CT scanning versus standard testing alone, the quality of the evidence was graded as moderate for all-cause mortality and cancer-related mortality due to the high risk of detection bias in Robin 2016. For VTE-related morbidity, the quality of the evidence was downgraded to moderate as only one study measured this outcome. For stage of cancer, the evidence was downgraded to low as there was imprecision due to low number of events and there was a high risk of detection bias (Summary of findings 2). The quality of evidence for type of cancer are presented in a summary of findings table in Appendix 4. For type of cancer, the evidence was judged to be moderate if there was imprecision due to low number of events or where the study was at high risk of detection bias. Where both imprecision and detection bias occurred together, the quality of the evidence was downgraded to low.

\section{Potential biases in the review process}

None of the authors of this review were involved in any of the included or excluded studies. Furthermore, none have any commercial or other conflict of interest. The search was as comprehensive as possible, and all studies were independently assessed for inclusion by two review authors. We are confident that we have included all relevant studies and we have attempted to reduce bias in the review process by performing data extraction and assessing study quality independently. However, the possibility remains that we may have missed studies that have not been published.

We judged blinding of investigators and participants to be at low risk of bias. It would have been impossible to blind participants and staff to tests such as scans. Therefore, there is a risk of crossover bias in participants in the control group with them having further tests. However, the effect of this would be to minimise the apparent benefit from testing that was observed, and, therefore, this does not detract from the conclusions of the study or review. In this review, we presented the studies by Piccioli 2004b and Prandoni 2016 together as both studies compared extensive tests for cancer versus "tests at the physicians discretion". The studies by Carrier 2015 and Robin 2016 were reported in a separate analysis as both studies compared limited screening plus PET/CT scanning versus limited screening alone. Combining all four studies in a meta-analysis would have been problematic due to the different definitions of the comparator groups. However, the control group of the Carrier 2015 and Robin 2016 studies included some of the tests in the test group of the studies by Piccioli 2004b and Prandoni 2016, which may account for why there was no clear difference observed, along with participation of all people in breast and colorectal cancer screening programmes. This may also be the reason for the very low incidence of cancer in the studies by Carrier 2015 and Robin 2016 compared to the studies by Piccioli 2004b and Prandoni 2016.

\section{Agreements and disagreements with other studies or reviews}

To date, no other systematic review has assessed the effectiveness of testing for cancer on cancer-related mortality in people with an unprovoked VTE.

\section{AUTHORS' CONCLUSIONS}

\section{Implications for practice}

At present, there is insufficient evidence as to whether testing for undiagnosed cancer in people with a first episode of unprovoked venous thromboembolism (VTE) (deep vein thrombosis (DVT) of the lower limb or pulmonary embolism (PE)) is effective in reducing cancer- and VTE-related mortality and morbidity, and which tests for cancer are best at identifying treatable cancers early. The decision whether to screen for cancer or not in a first episode of unprovoked VTE remains for individual clinicians and participants to decide on a case-by-case basis. The diagnosis of cancer has significant implications for participants and may alter the pharmacological treatment of their VTE, and some may wish to be investigated even in the absence of a survival benefit.

\section{Implications for research}

The low number of studies in this systematic review confirms the need for further methodologically sound and large randomised controlled trials. They should be adequately powered to look at key endpoints including mortality, as well as addressing questions concerning the types of test to be used, quality of life and participant preference.

\section{ACKNOWLEDGEMENTS}

The review authors would like to thank the Cochrane Vascular editorial base for their guidance for this review. 


\section{REFERE N C ES}

\section{References to studies included in this review}

\section{Carrier 2015 \{published data only\}}

Carrier M, Lazo-Langner A, Shivakumar S, Tagalakis V, Zarychanski R, Solymoss S, et al. Screening for occult cancer in unprovoked venous thromboembolism. New England Journal of Medicine 2015;373(8):697-704.

\section{Piccioli 2004b \{published data only\}}

Otten HM, Prins MH. A number needed to screen and cost-effectiveness analysis of the SOMIT-data. Haemostasis 2001;31 Suppl 1:40-2.

* Piccioli A, Lensing AWA, Prins MH, Falanga A, Scannapieco GL, Ieran M, et al. Extensive screening for occult malignant disease in idiopathic venous thromboembolism: a prospective randomized clinical trial. Journal of Thrombosis and Haemostasis 2004;2:884-9.

Prandoni 2016 \{published data only\}

Piccioli A. The value of CT scanning for detection of occult cancer in patients with idiopathic VTE. Cancer, thrombosis and low-molecular-weight heparins (dare.uva.nll record/1/465654 (accessed June 2016)). Amsterdam (the Netherlands): University of Amsterdam, 2015. Piccioli A, Bernardi E, Dalla Valle F, Visona A, Tropeano $\mathrm{F}$, Bova $\mathrm{C}$, et al. The value of CT-scanning for detection of occult cancer in patients with unprovoked venous thromboembolism. The D'Acquapendente study. Journal of Thrombosis and Haemostasis 2013;11 (Suppl 2):50-1. Piccioli $\mathrm{A}$, Bernardi E, Dalla Valle F, Visonà $\mathrm{A}$, Tropeano PF, Bova $\mathrm{C}$, et al. The value of thoraco-abdominal CT scanning for the detection of occult cancer in patients with unprovoked venous thromboembolism. A randomized study. Thrombosis Research 2012;129 Suppl 1:S155-94. * Prandoni P, Bernardi E, Valle FD, Visona A, Tropeano PF, Bova C, et al. Extensive computed tomography versus limited screening for detection of occult cancer in unprovoked venous thromboembolism: a multicenter, controlled, randomized clinical trial. Seminars in Thrombosis and Hemostasis 2016;42(8):884-90.

Robin 2016 \{published data only\}

Robin P, Le Roux PY, Planquette B, Accassat S, Roy PM, Couturaud F, et al. Limited screening with versus without (18)F-fluorodeoxyglucose PET/CT for occult malignancy in unprovoked venous thromboembolism: an open-label randomised controlled trial. Lancet Oncology 2016;17(2): 193-9.

\section{Additional references}

\section{Atkins 2004}

Atkins D, Best D, Briss PA, Eccles M, Falck-Ytter Y,

Flottorp S, et al. GRADE Working Group. Grading quality of evidence and strength of recommendations. BMJ 2004; 328(7454):1490-4.
Baron 1998

Baron JA, Gridley G, Weiderpass E, Nyren O, Linet M. Venous thromboembolism and cancer. Lancet 1998;351 (9109):1077-80.

\section{Bick 1978}

Bick RL. Alterations of hemostasis associated with malignancy: etiology, pathophysiology, diagnosis and management. Seminars in Thrombosis and Hemostasis 1978; 5(1):1-26.

\section{Blann 2006}

Blann AD, Lip GYH. Venous thromboembolism. BMJ 2006;332(7535):215-9.

\section{Carrier 2014}

Carrier M, Cameron C, Delluc A, Castellucci L, Khorana AA, Lee AY. Efficacy and safety of anticoagulant therapy for the treatment of acute cancer-associated thrombosis: a systematic review and meta-analysis. Thrombosis Research 2014;134(6):1214-9.

\section{Deeks 2011}

Deeks JJ, Higgins JPT, Altman DG. Chapter 9: Analysing data and undertaking meta-analyses. In: Higgins JPT, Green S, editor(s). Cochrane Handbook for Systematic Reviews of Interventions Version 5.1.0 (updated March 2011). The Cochrane Collaboration, 2011. Available from handbook.cochrane.org.

Higgins 2011

Higgins JPT, Altman DG, Sterne JAC. Chapter 8: Assessing risk of bias in included studies. In: Higgins JPT, Green S, editor(s). Cochrane Handbook for Systematic Reviews of Interventions Version 5.1.0 (updated March 2011). The Cochrane Collaboration, 2011. Available from handbook.cochrane.org.

\section{Kakkar 2003}

Kakkar AK, Levine M, Pinedo HM, Wolff R, Wong J. Venous thrombosis in cancer patients: insights from the FRONTLINE survey. Oncologist 2003;8(4):381-8.

\section{Lee 2003a}

Lee AY, Levine MN. Venous thromboembolism and cancer: risks and outcomes. Circulation 2003;107(23 Suppl 1): I17-21.

Lee 2003b

Lee AYY, Levine MN, Baker RI, Bowden C, Kakkar AK, Prins M, et al. Low-molecular-weight heparin versus a coumarin for the prevention of recurrent venous thromboembolism in patients with cancer. New England Journal of Medicine 2003;349(2):146-53.

Levitan 1999

Levitan N, Dowlati A, Remick SC, Tahsildar HI, Sivinski $\mathrm{LD}$, Beyth R, et al. Rates of initial and recurrent thromboembolic disease among patients with malignancy versus those without malignancy. Risk analysis using Medicare claims data. Medicine (Baltimore) 1999;78(5): 285-91.

Effect of testing for cancer on cancer- and venous thromboembolism (VTE)-related mortality and morbidity in people with unprovoked 


\section{NICE 2012}

National Institute for Health and Care Excellence. Venous thromboembolic diseases: the management of venous thromboembolic diseases and the role of thrombophilia testing. NICE Clinical Guideline 144. www.nice.org.uk/ guidance/cg144 (accessed 2 August 2017).

\section{Piccioli 2004a}

Piccioli A, Lensing AW, Prins MH, Falanga A, Scannapieco GL, Ieran M, et al. SOMIT Investigators Group. Extensive screening for occult malignant disease in idiopathic venous thromboembolism: a prospective randomized clinical trial. Journal of Thrombosis and Haemostasis 2004;2(6):884-9.

\section{Prandoni 1997}

Prandoni P, Piccioli A. Venous thromboembolism and cancer: a two-way clinical association. Frontiers in Bioscience 1997;2:e12-21.

\section{RevMan 2014 [Computer program]}

The Nordic Cochrane Centre, The Cochrane Collaboration. Review Manager (RevMan). Version 5.3. Copenhagen: The Nordic Cochrane Centre, The Cochrane Collaboration, 2014.

\section{Sorensen 2000}

Sorensen HT, Mellemkjaer L, Olsen JH, Baron JA. Prognosis of cancers associated with venous thromboembolism. New England Journal of Medicine 2000;343:1846-50.

\section{Sterne 2011}

Sterne JAC, Egger M, Moher D. Chapter 10: Addressing reporting biases. In: Higgins JPT, Green S, editor

(s). Cochrane Handbook for Systematic Reviews of
Interventions. Version 5.1.0 (updated March 2011). The Cochrane Collaboration, 2011. Available from handbook.cochrane.org.

Vedovati 2015

Vedovati MC, Germini F, Agnelli G, Becattini C. Direct oral anticoagulants in patients with VTE and cancer: a systematic review and meta-analysis. Chest 2015;147(2): 475-83.

White 2005

White RH, Chew HK, Zhou H, Parikh-Patel A, Harris D, Harvey D, et al. Incidence of venous thromboembolism in the year before the diagnosis of cancer in 528,693 adults. Archives of Internal Medicine 2005;165(15):1782-7.

\section{References to other published versions of this review}

\section{Robertson 2013}

Robertson L, Agarwal R, Yeoh SE. Effect of testing for cancer on cancer- and venous thromboembolism (VTE)related mortality and morbidity in patients with unprovoked VTE. Cochrane Database of Systematic Reviews 2013, Issue 11. [DOI: 10.1002/14651858.CD010837

\section{Robertson 2015}

Robertson L, Yeoh SE, Stansby G, Agarwal R. Effect of testing for cancer on cancer- and venous thromboembolism (VTE)-related mortality and morbidity in patients with unprovoked VTE. Cochrane Database of Systematic Reviews 2015, Issue 3. [DOI: 10.1002/14651858.CD010837.pub2

* Indicates the major publication for the study 


\section{CHARACTERISTICS OF STUDIES}

\section{Characteristics of included studies [ordered by study ID]}

\section{Carrier 2015}

Methods

Participants

Study design: multicentre, open-label, randomised controlled trial Source of funding: Heart and Stroke Foundation of Canada.

Country: Canada.

Setting: hospital.

Number of centres: 9.

Number of participants: 854 .

Age (mean (SD)): screening + CT group: 53.4 (14.2) years; screening only group: 53.7 (13.8)

Sex: screening + CT group: 299 M/124 F; screening only group: 277 M/154 F

Inclusion criteria: people with new diagnosis of first unprovoked VTE (proximal lowerlimb deep vein thrombosis, pulmonary embolism, or both). Unprovoked VTE defined as VTE in absence of known overt active cancer, current pregnancy, thrombophilia (hereditary or acquired), previous unprovoked VTE or a temporary predisposing factor in the previous 3 months, including paralysis, paresis or plaster immobilisation of the legs, confinement to bed for $\geq 3$ days or major surgery

Exclusion criteria: aged $<18$ years, refusal or inability to provide informed consent, allergy to contrast media, creatinine clearance $<60 \mathrm{~mL}$ per minute, claustrophobia or agoraphobia, weight $>130 \mathrm{~kg}$, ulcerative colitis or glaucoma

Interventions

Screening procedure: complete history and physical examination, measurement of complete blood counts and serum electrolyte and creatinine levels, liver-function testing and chest radiography. Sex-specific screening conducted if it had not been performed in previous year. Breast examination, mammography, or both performed in women $>50$ years of age and Pap testing and a pelvic examination performed in women 18-70 years of age who had never been sexually active. Prostate examination, PSA test, or both performed in men aged $>40$ years. Also comprehensive CT of abdomen and pelvis (virtual colonoscopy and gastroscopy, biphasic enhanced CT of liver, parenchymal pancreatography, and uniphasic enhanced CT of distended bladder)

Control: complete history and physical examination, measurement of complete blood counts and serum electrolyte and creatinine levels, liver-function testing and chest radiography. Sex-specific screening conducted if it had not been performed in previous year. Breast examination, mammography, or both performed in women $>50$ years of age and Pap testing and a pelvic examination performed in women 18-70 years of age who had ever been sexually active. Prostate examination, PSA test, or both performed in men aged $>40$ years

Duration: 1 year follow-up.

Outcomes

Primary outcomes: newly diagnosed cancer during the follow-up period in people who had a negative screening result for occult cancer

Secondary outcomes: total number of occult cancers diagnosed and total number of early cancers $\left(\mathrm{T}_{1-2}, \mathrm{~N}_{0}, \mathrm{M}_{0}\right.$ according to the World Health Organization TNM classification system) diagnosed by occult-cancer screening and during subsequent 1-year follow-up, 1 -year cancer-related mortality, 1-year overall mortality, time to cancer diagnosis and

Effect of testing for cancer on cancer- and venous thromboembolism (VTE)-related mortality and morbidity in people with unprovoked 24 VTE (Review)

Copyright $\odot 2017$ The Cochrane Collaboration. Published by John Wiley \& Sons, Ltd. 


\begin{tabular}{|c|c|c|}
\hline Notes & & \\
\hline \multicolumn{3}{|l|}{ Risk of bias } \\
\hline Bias & Authors' judgement & Support for judgement \\
\hline $\begin{array}{l}\text { Random sequence generation (selection } \\
\text { bias) }\end{array}$ & Low risk & $\begin{array}{l}\text { Quote: "The trial statistician generated the } \\
\text { randomisation list using random-number } \\
\text { tables." }\end{array}$ \\
\hline Allocation concealment (selection bias) & Low risk & $\begin{array}{l}\text { Quote: "A central Web-based randomisa- } \\
\text { tion system ensured assignment conceal- } \\
\text { ment." }\end{array}$ \\
\hline $\begin{array}{l}\text { Blinding of participants and personnel } \\
\text { (performance bias) } \\
\text { All outcomes }\end{array}$ & Low risk & $\begin{array}{l}\text { Comment: blinding of participants and } \\
\text { study personnel not done but review au- } \\
\text { thors judged that outcome and outcome } \\
\text { measurement not likely to be influenced by } \\
\text { lack of blinding }\end{array}$ \\
\hline $\begin{array}{l}\text { Blinding of outcome assessment (detection } \\
\text { bias) } \\
\text { All outcomes }\end{array}$ & Low risk & $\begin{array}{l}\text { Quote: "A central adjudication committee } \\
\text { whose members were unaware of the study- } \\
\text { group assignments reviewed all suspected } \\
\text { outcome events." } \\
\text { Comment: outcome assessors blinded to } \\
\text { study allocation. }\end{array}$ \\
\hline $\begin{array}{l}\text { Incomplete outcome data (attrition bias) } \\
\text { All outcomes }\end{array}$ & Low risk & $\begin{array}{l}\text { Comment: all losses to follow-up ac- } \\
\text { counted for. }\end{array}$ \\
\hline Selective reporting (reporting bias) & Low risk & $\begin{array}{l}\text { Comment: primary and secondary out- } \\
\text { comes clearly prespecified and reported }\end{array}$ \\
\hline Other bias & Low risk & $\begin{array}{l}\text { Comment: study appeared free from other } \\
\text { sources of bias. }\end{array}$ \\
\hline
\end{tabular}

\section{Piccioli 2004b}

Methods

Participants
Study design: randomised multicentre clinical trial.

Source of funding: Associazone Italiana per le Ricerca sul Cancro

Country: Italy.

Setting: hospital.

Number of centres: not stated.

Number of participants: 201.

Age (mean (SD)): screening group: 66.2 (13.1) years; no screening group: 66.6 (13.1) years 
Sex: screening group: $54 \mathrm{M} / 45 \mathrm{~F}$; no screening group: $46 \mathrm{M} / 56 \mathrm{~F}$

Inclusion criteria: apparently cancer-free people with a documented unprovoked first episode of symptomatic deep vein thrombosis of the lower extremity or pulmonary embolism

Exclusion criteria: recognised risk factor for VTE (malignant disease, trauma of the leg, surgical procedures or immobilisation within 6 months, confirmed spontaneous VTE in a first-degree relative, deficiency of antithrombin, protein $\mathrm{C}$ or $\mathrm{S}$, presence of circulating lupus anticoagulant, oestrogen use, pregnancy or childbirth), previously documented VTE, malignant disease identified at routine physical examination, history taking, laboratory assessment or chest X-ray at referral, unable to attend follow-up due to geographic inaccessibility and aged $<25$ years

Interventions

Screening procedure: combination of ultrasound and CT scan of abdomen and pelvis, gastroscopy or double-contrast barium swallow, flexible sigmoidoscopy or rectoscopy followed by barium enema or colonoscopy, haemoccult, sputum cytology and tumour markers including carcinoembryonic antigen, $\alpha$-fetoprotein and CA125. In addition, women had gynaecological examination, Pap smear and mammography. Men had a transabdominal ultrasound of prostate and total PSA test

Control: tests at physician's discretion.

Duration: 2-year follow-up. At these visits, special attention paid to recent medical history. To avoid diagnostic suspicion bias, medical history concerning general health, hospital admission, and occurrence of signs and symptoms of cancer obtained on a standardised form by a physician unaware of allocation of participant. If malignant disease had become apparent during follow-up, information from the attending specialist sought after consent of participant

Outcomes

Primary outcomes: cancer-related mortality defined as death due to a malignant disease itself, or death due to complications of diagnostic or surgical procedures performed to diagnose or treat cancer

Secondary outcomes: cluster of cancer-related mortality and presence of objectively documented residual malignancy or recurrent malignancy at 24 months and sensitivity of the diagnostic work-up for occult malignancy

Notes

\section{Risk of bias}

Bias

Random sequence generation (selection Low risk bias)

Allocation concealment (selection bias) Low risk

Blinding of participants and personnel Low risk (performance bias)

All outcomes

\section{Support for judgement}

Quote: "According to the Zelen design, patients randomised to..."

Quote: "Randomisation was performed centrally."

Quote: "Patients randomised to extensive screening were informed about the study. As patients allocated to the control group were not informed about the study, patients

Effect of testing for cancer on cancer- and venous thromboembolism (VTE)-related mortality and morbidity in people with unprovoked 
Piccioli 2004b (Continued)

and their physicians were not discouraged to search for malignant disease."

Comment: blinding of participants in extensive screening group and study personnel not done but review authors judged that outcome and outcome measurement not likely to be influenced by lack of blinding

Blinding of outcome assessment (detection Low risk bias)

All outcomes
Quote: "To avoid diagnostic suspicion bias, the medical history concerning general health, hospital admission and occurrence of signs and symptoms of cancer were obtained on a standardised form by a physician unaware of allocation of the patient." Comment: outcome assessors blinded to study allocation.

Comment: all participants completed the 2-year follow-up. No missing data

ncomplete outcome data (attrition bias) Low risk All outcomes

Selective reporting (reporting bias) Low risk

High risk

Comment: primary and secondary outcomes clearly prespecified and reported

Other bias

Comment: study terminated early after inclusion of only 201 participants after 5 years for several reasons. First, only 5 of the more than 40 potential participating centres could contribute participants to the study. Second, some medical ethics committees rejected the protocol because of the absence of screening for occult cancer in the control group, other centres could not start because the proposed extensive screening was judged to be unethical. Finally, identification of cancer at an apparent early stage in the extensive screening group led to an increasing tendency among physicians in participating hospitals to initiate screening for cancer in control participants

Prandoni 2016

Methods

Study design: multicentre, randomised controlled trial.

Participants

Country: Italy.

Setting: hospital.

Number of centres: 5 .

Number of participants: 195

Effect of testing for cancer on cancer- and venous thromboembolism (VTE)-related mortality and morbidity in people with unprovoked 
Age (mean (SD)): extensive screening group: 69.3 (14) years; control group: 69.0 (14) years

Sex: extensive screening group: $54 \mathrm{M} / 44 \mathrm{~F}$; control group: $47 \mathrm{M} / 50 \mathrm{~F}$

Inclusion criteria: people with an objectively diagnosed, first episode of unprovoked VTE, in whom a routine initial screening for cancer was normal

Exclusion criteria: history of previous documented episodes of VTE, aged $<18$ years, pregnant, unable to attend follow-up visits because of geographic inaccessibility, had known allergy to contrast medium or had a CT scan of torso for any reasons within 6 months from presentation

Interventions

Screening procedure: extensive screening with mandatory CT scan of thorax, abdomen and pelvis together with haemoccult test or any test at physician's discretion according to good clinical practice

Control: personalised strategy consisting of additional testing based on physicians' judgements and participants' preferences, including a 'no-further testing' option

Duration: 3, 6, 12 and 24 month' follow-up in which participants were asked about general health, history of recent hospital admissions and occurrence of signs and symptoms suggestive of cancer. Cancer outcomes that presented during follow-up were detected based on clinical features that would prompt diagnostic imaging or cancers that were occasionally detected by screening that was independent of the diagnosis of VTE

Outcomes

Primary outcomes: cancer-related mortality (defined as death due to malignancy or death due to the complications of the diagnostic or surgical procedures performed to diagnose or treat cancer) and incidence of newly discovered cancer

Secondary outcomes: cancer stage, using the TNM classification, at which tumours were diagnosed in the 2 study groups; and incidence of cancer-related mortality in the 2 randomisation groups

Notes

Risk of bias

\section{Bias}

Random sequence generation (selection Low risk bias)

\section{Authors' judgement}

(n)

Allocation concealment (selection bias) Low risk

\section{Support for judgement}

Quote: “Concealed allocation was ensured by employing serially numbered, opaque, sealed envelopes. Each participating centre was initially assigned a lot of 20 envelopes, while subsequent allocations were in lots of 10 , as needed."

Quote: "Concealed allocation was ensured by employing serially numbered, opaque, sealed envelopes. Each participating centre was initially assigned a lot of 20 envelopes, while subsequent allocations were in lots of 10 , as needed."

Effect of testing for cancer on cancer- and venous thromboembolism (VTE)-related mortality and morbidity in people with unprovoked 
Blinding of participants and personnel Low risk (performance bias)

All outcomes
Comment: blinding of participants in extensive screening group and study personnel not done but review authors judged that outcome and outcome measurement were not likely to be influenced by lack of blinding

Blinding of outcome assessment (detection Low risk bias)

All outcomes

Comment: investigators performing the follow-up visits blinded to participants' randomisation groups'

Incomplete outcome data (attrition bias) Low risk All outcomes

Comment: all losses to follow-up accounted for.

Selective reporting (reporting bias) Low risk

Comment: primary and secondary outcomes clearly prespecified and reported

Other bias

High risk
Comment: interim analysis scheduled after inclusion of approximately half of planned sample size. Based on results of this analysis, study promoters decided to stop study enrolment because of low recruitment rate and of failure to show an appreciable advantage of CT-based strategy over control strategy for detection of occult cancers

\section{Robin 2016}

Methods

Participants
Study design: open-label, multicentre, randomised study. Source of funding: Programme Hospitalier de Recherche Clinique (French Department of Health)

\section{Country: France.}

Setting: hospital.

Number of centres: 4.

Number of participants: 394.

Age (mean (range)): screening group: 64 (48-77) years; limited screening group: 62 (5075) years

Sex: screening group: $105 \mathrm{M} / 92 \mathrm{~F}$; limited screening group: $102 \mathrm{M} / 95 \mathrm{~F}$

Inclusion criteria: aged $\geq 18$ years, diagnosed with unprovoked VTE. VTE defined as objectively confirmed proximal deep vein thrombosis or pulmonary embolism. Unprovoked VTE defined as VTE not provoked by major inherited or acquired risk factor including surgery, trauma or fracture during 3 months before VTE event, known antiphospholipid antibody syndrome or known deficiency in antithrombin, protein $\mathrm{C}$ or protein $S$

Exclusion criteria: ongoing pregnancy, active malignant disease (defined as known malignant disease which was active or treated during previous 5 years), not insured under French National Social Security programme, hypersensitivity to ${ }^{18}$ F-FDG or any of the 
Robin 2016 (Continued)

excipients according to summary of product characteristics in France, or unable or unwilling to give consent

Interventions

Screening procedure: screening strategy consisting of limited strategy $+{ }^{18} \mathrm{~F}-\mathrm{FDG}$ PET/ CT scan of chest, abdomen and pelvis.

Control: limited screening strategy (physical examination, usual laboratory tests and

basic radiographs)

Duration: 2 years.

Outcomes

Primary outcomes: proportion of people with a cancer diagnosis in each group after the initial screening assessment

Secondary outcomes: subsequent cancer diagnosis in people with negative initial screening, proportion of early-stage versus advanced-stage tumours at initial screening and during follow-up, overall mortality and cancer-related mortality during follow-up

Notes

Risk of bias

Bias

Random sequence generation (selection Low risk bias)

Allocation concealment (selection bias) Low risk

Blinding of participants and personnel Low risk (performance bias)

All outcomes

\section{Support for judgement}

Quote: "The randomisation list was created centrally using computer-generated block sizes of six, stratified by centre, and concealed from investigators. We used a secure, dedicated, central web-based randomisation system (Clinsight)."

Quote: "The randomisation list was created centrally using computer-generated block sizes of six, stratified by centre, and concealed from investigators. We used a secure, dedicated, central web-based randomisation system (Clinsight). A unique study participant number and study group allocation was given after patients' basic information and eligibility criteria were entered by the study personnel."

Quote: "Participants and physicians giving the intervention, assessing outcomes, and analysing the data were not masked to study group assignment."

Comment: blinding of participants and study personnel not done but review authors judged that outcome and outcome measurement not likely to be influenced by lack of blinding 
Robin 2016 (Continued)

\begin{tabular}{|c|c|c|}
\hline $\begin{array}{l}\text { Blinding of outcome assessment (detection } \\
\text { bias) } \\
\text { All outcomes }\end{array}$ & High risk & $\begin{array}{l}\text { Quote: "Physicians giving the intervention, } \\
\text { assessing outcomes, and analysing the data } \\
\text { were not masked to study group assign- } \\
\text { ment." } \\
\text { Comment: outcome assessors not blinded } \\
\text { to outcome assessment }\end{array}$ \\
\hline $\begin{array}{l}\text { Incomplete outcome data (attrition bias) } \\
\text { All outcomes }\end{array}$ & Low risk & $\begin{array}{l}\text { Comment: all losses to follow-up ac- } \\
\text { counted for. }\end{array}$ \\
\hline Selective reporting (reporting bias) & Low risk & $\begin{array}{l}\text { Comment: primary and secondary out- } \\
\text { comes clearly prespecified and reported }\end{array}$ \\
\hline Other bias & Low risk & $\begin{array}{l}\text { Comment: study appeared free from other } \\
\text { sources of bias. }\end{array}$ \\
\hline
\end{tabular}

CT: computed tomography; F: female; FDG: fluorodeoxyglucose; M: male; Pap: Papanicolaou; PET: positron emission tomography; PSA: prostate-specific antigen; SD: standard deviation; TNM: tumour-node-metastasis; VTE: venous thromboembolism. 
DATA AND ANALYSES

Comparison 1. Extensive tests versus tests at the physician's discretion

\begin{tabular}{|c|c|c|c|c|}
\hline Outcome or subgroup title & $\begin{array}{l}\text { No. of } \\
\text { studies }\end{array}$ & $\begin{array}{c}\text { No. of } \\
\text { participants }\end{array}$ & Statistical method & Effect size \\
\hline 1 Cancer-related mortality & 2 & 396 & Odds Ratio (M-H, Random, 95\% CI) & $0.49[0.15,1.67]$ \\
\hline $\begin{array}{l}2 \text { Characteristics of diagnosed } \\
\text { cancer: type of cancer }\end{array}$ & 1 & & Odds Ratio (M-H, Random, 95\% CI) & Subtotals only \\
\hline 2.1 Lung & 1 & 201 & Odds Ratio (M-H, Random, 95\% CI) & $2.08[0.19,23.34]$ \\
\hline 2.2 Bladder & 1 & 201 & Odds Ratio (M-H, Random, 95\% CI) & $2.08[0.19,23.34]$ \\
\hline 2.3 Stomach & 1 & 201 & Odds Ratio (M-H, Random, 95\% CI) & $1.03[0.06,16.71]$ \\
\hline 2.4 Kidney & 1 & 201 & Odds Ratio (M-H, Random, 95\% CI) & $3.12[0.13,77.55]$ \\
\hline 2.5 Adrenal gland & 1 & 201 & Odds Ratio (M-H, Random, 95\% CI) & $3.12[0.13,77.55]$ \\
\hline 2.6 Liver & 1 & 201 & Odds Ratio (M-H, Random, 95\% CI) & $3.12[0.13,77.55]$ \\
\hline 2.7 Uterus & 1 & 201 & Odds Ratio (M-H, Random, 95\% CI) & $3.12[0.13,77.55]$ \\
\hline 2.8 Breast & 1 & 201 & Odds Ratio (M-H, Random, 95\% CI) & $1.03[0.06,16.71]$ \\
\hline 2.9 Ovary & 1 & 201 & Odds Ratio (M-H, Random, 95\% CI) & $3.12[0.13,77.55]$ \\
\hline 2.10 Colon & 1 & 201 & Odds Ratio (M-H, Random, 95\% CI) & $0.51[0.05,5.72]$ \\
\hline 2.11 Prostate & 1 & 201 & Odds Ratio (M-H, Random, 95\% CI) & $0.51[0.05,5.72]$ \\
\hline 2.12 Pancreas & 1 & 201 & Odds Ratio (M-H, Random, 95\% CI) & $0.20[0.01,4.26]$ \\
\hline $\begin{array}{l}3 \text { Characteristics of diagnosed } \\
\text { cancer: stage of cancer }\end{array}$ & 1 & & Odds Ratio (M-H, Random, 95\% CI) & Subtotals only \\
\hline $3.1 \mathrm{~T} 1$ or $\mathrm{T} 2$ (N0 M0) & 1 & 201 & Odds Ratio (M-H, Random, 95\% CI) & $5.00[1.05,23.76]$ \\
\hline $3.2 \mathrm{~T} 3$ & 1 & 201 & Odds Ratio (M-H, Random, 95\% CI) & $0.25[0.03,2.28]$ \\
\hline $\begin{array}{l}4 \text { Frequency of underlying cancer } \\
\text { diagnosis }\end{array}$ & 2 & 396 & Odds Ratio (M-H, Random, 95\% CI) & $1.32[0.59,2.93]$ \\
\hline
\end{tabular}

Comparison 2. Standard testing plus PET/CT scanning versus standard testing alone

\begin{tabular}{|c|c|c|c|c|}
\hline Outcome or subgroup title & $\begin{array}{l}\text { No. of } \\
\text { studies }\end{array}$ & $\begin{array}{c}\text { No. of } \\
\text { participants }\end{array}$ & Statistical method & Effect size \\
\hline 1 All-cause mortality & 2 & 1248 & Odds Ratio (M-H, Random, 95\% CI) & $1.22[0.49,3.04]$ \\
\hline 2 Cancer-related mortality & 2 & 1248 & Odds Ratio (M-H, Random, 95\% CI) & $0.55[0.20,1.52]$ \\
\hline $\begin{array}{l}3 \text { Venous } \\
\text { thromboembolism-related } \\
\text { morbidity }\end{array}$ & 1 & 854 & Odds Ratio (M-H, Random, 95\% CI) & $1.02[0.48,2.17]$ \\
\hline $\begin{array}{l}4 \text { Characteristics of diagnosed } \\
\text { cancer: type of cancer }\end{array}$ & 2 & & Odds Ratio (M-H, Random, 95\% CI) & Subtotals only \\
\hline 4.1 Acute leukaemia & 2 & 1248 & Odds Ratio (M-H, Random, 95\% CI) & $1.62[0.20,13.22]$ \\
\hline 4.2 Gynaecological & 2 & 1248 & Odds Ratio (M-H, Random, 95\% CI) & $2.39[0.43,13.36]$ \\
\hline 4.3 Skin: melanoma & 1 & 854 & Odds Ratio (M-H, Random, 95\% CI) & $1.02[0.06,16.34]$ \\
\hline 4.4 Colorectal & 2 & 1248 & Odds Ratio (M-H, Random, 95\% CI) & $0.43[0.08,2.40]$ \\
\hline 4.5 Prostate & 2 & 1248 & Odds Ratio (M-H, Random, 95\% CI) & $2.52[0.48,13.12]$ \\
\hline 4.6 Pancreatic & 2 & 1248 & Odds Ratio (M-H, Random, 95\% CI) & $4.81[0.55,42.48]$ \\
\hline
\end{tabular}

Effect of testing for cancer on cancer- and venous thromboembolism (VTE)-related mortality and morbidity in people with unprovoked 32 VTE (Review)

Copyright @ 2017 The Cochrane Collaboration. Published by John Wiley \& Sons, Ltd. 
4.7 Cholangiocarcinoma

4.8 Lymphoma

4.9 Breast

4.10 Urological

4.11 Liver

4.12 Head and neck

4.13 Lung

4.14 Unknown primary

5 Characteristics of diagnosed cancer: stage of cancer

5.1 Early

5.2 Advanced

6 Frequency of an underlying cancer diagnosis
Odds Ratio (M-H, Random, 95\% CI)

Odds Ratio (M-H, Random, 95\% CI)

Odds Ratio (M-H, Random, 95\% CI)

Odds Ratio (M-H, Random, 95\% CI)

Odds Ratio (M-H, Random, 95\% CI)

Odds Ratio (M-H, Random, 95\% CI)

Odds Ratio (M-H, Random, 95\% CI)

Odds Ratio (M-H, Random, 95\% CI)

Odds Ratio (M-H, Random, 95\% CI)

Odds Ratio (M-H, Random, 95\% CI)

Odds Ratio (M-H, Random, 95\% CI)

Odds Ratio (M-H, Random, 95\% CI)
$0.51[0.05,5.63]$

$0.74[0.09,5.83]$

$0.20[0.01,4.24]$

$0.62[0.03,12.32]$

$0.33[0.01,8.19]$

$3.02[0.12,74.47]$

$3.02[0.12,74.47]$

$0.34[0.01,8.34]$

Subtotals only

$1.78[0.51,6.17]$

$1.0[0.14,7.17]$

$1.71[0.91,3.20]$

\section{Analysis I.I. Comparison I Extensive tests versus tests at the physician's discretion, Outcome I Cancer-}

related mortality.

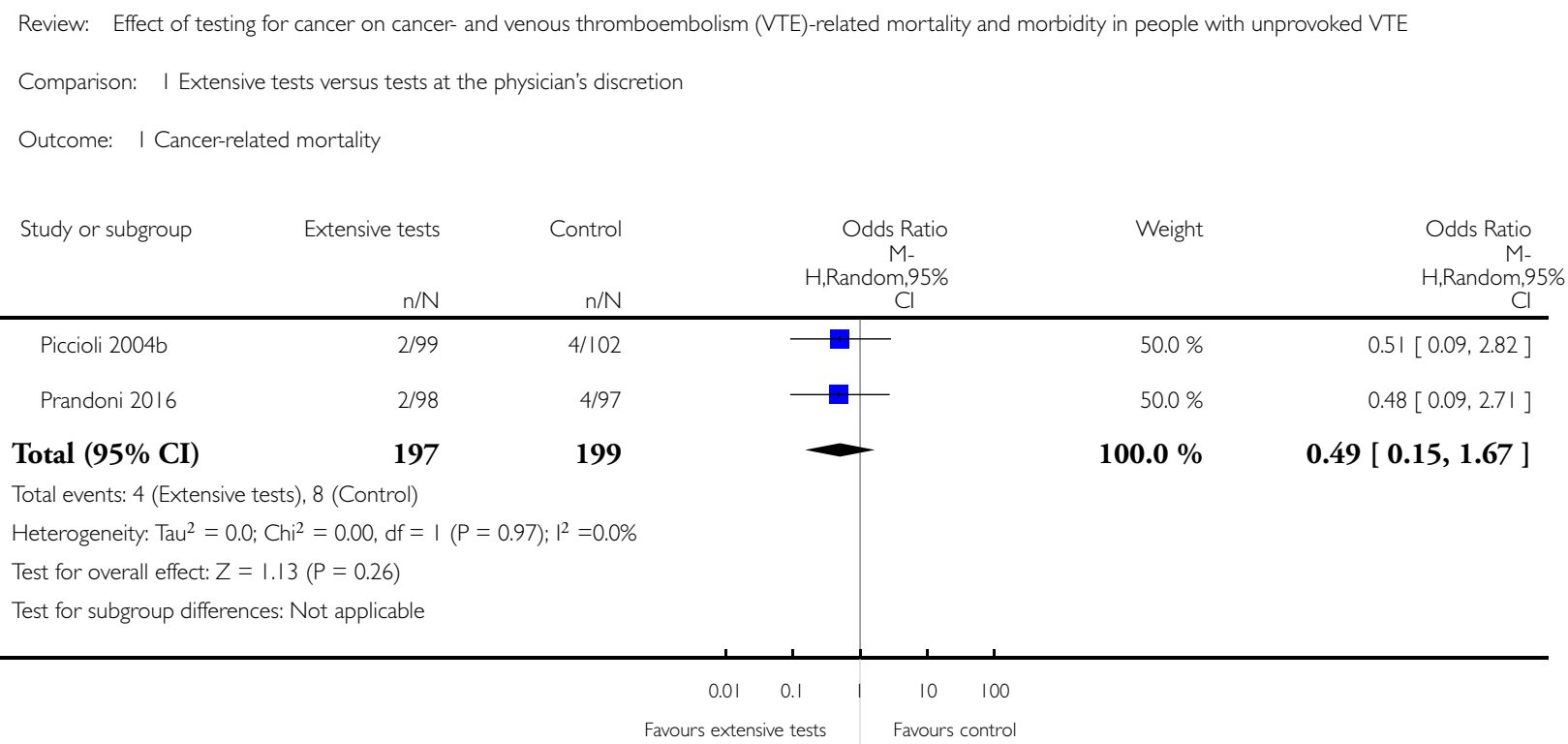




\section{Analysis I.2. Comparison I Extensive tests versus tests at the physician's discretion, Outcome 2 Characteristics of diagnosed cancer: type of cancer.}

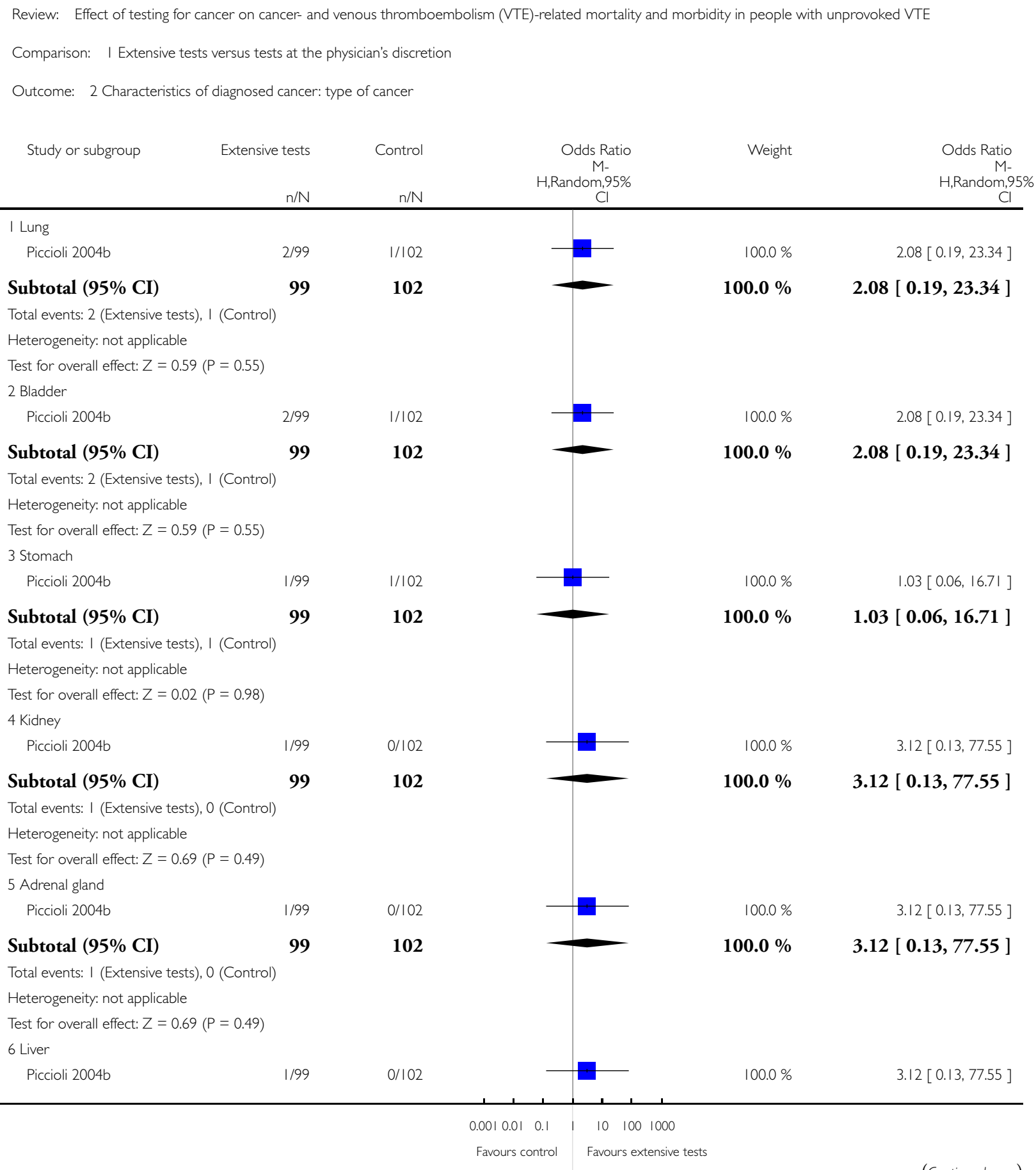

(Continued....)

Effect of testing for cancer on cancer- and venous thromboembolism (VTE)-related mortality and morbidity in people with unprovoked 34 VTE (Review)

Copyright $@ 2017$ The Cochrane Collaboration. Published by John Wiley \& Sons, Ltd. 


\begin{tabular}{|c|c|c|c|c|c|}
\hline Study or subgroup & Extensive tests & $\begin{array}{r}\text { Control } \\
n / N \\
\end{array}$ & $\begin{array}{c}\text { Odds Ratio } \\
\text { M- } \\
\mathrm{H} \text {,Random, } 95 \% \\
\mathrm{Cl} \\
\end{array}$ & Weight & $\begin{array}{c}\text { (... Continued) } \\
\text { Odds Ratio } \\
\text { M- } \\
\text { H,Random,95\% } \\
\mathrm{Cl} \\
\end{array}$ \\
\hline Subtotal $(95 \% \mathrm{CI})$ & 99 & 102 & & $100.0 \%$ & $3.12[0.13,77.55]$ \\
\hline \multicolumn{6}{|c|}{ Total events: I (Extensive tests), 0 (Control) } \\
\hline \multicolumn{6}{|c|}{ Heterogeneity: not applicable } \\
\hline \multicolumn{6}{|c|}{ Test for overall effect: $Z=0.69(P=0.49)$} \\
\hline \multicolumn{6}{|c|}{7 Uterus } \\
\hline Piccioli 2004b & 1/99 & 0/102 & & $100.0 \%$ & $3.12[0.13,77.55]$ \\
\hline Subtotal $(95 \% \mathrm{CI})$ & 99 & 102 & & $100.0 \%$ & $3.12[0.13,77.55]$ \\
\hline \multicolumn{6}{|c|}{ Total events: I (Extensive tests), 0 (Control) } \\
\hline \multicolumn{6}{|c|}{ Heterogeneity: not applicable } \\
\hline \multicolumn{6}{|c|}{ Test for overall effect: $Z=0.69(P=0.49)$} \\
\hline \multicolumn{6}{|l|}{8 Breast } \\
\hline Piccioli 2004b & 1/99 & $1 / 102$ & & $100.0 \%$ & $1.03[0.06,16.71]$ \\
\hline Subtotal $(95 \% \mathrm{CI})$ & 99 & 102 & & $100.0 \%$ & $1.03[0.06,16.71]$ \\
\hline \multicolumn{6}{|c|}{ Total events: I (Extensive tests), I (Control) } \\
\hline \multicolumn{6}{|c|}{ Heterogeneity: not applicable } \\
\hline \multicolumn{6}{|c|}{ Test for overall effect: $Z=0.02(P=0.98)$} \\
\hline \multicolumn{6}{|c|}{9 Ovary } \\
\hline Piccioli 2004b & 1/99 & 0/102 & & $100.0 \%$ & $3.12[0.13,77.55]$ \\
\hline Subtotal (95\% CI) & 99 & 102 & & $100.0 \%$ & $3.12[0.13,77.55]$ \\
\hline \multicolumn{6}{|c|}{ Total events: I (Extensive tests), 0 (Control) } \\
\hline \multicolumn{6}{|l|}{ Heterogeneity: not applicable } \\
\hline \multicolumn{6}{|c|}{ Test for overall effect: $Z=0.69(P=0.49)$} \\
\hline \multicolumn{6}{|l|}{10 Colon } \\
\hline Piccioli 2004b & 1/99 & $2 / 102$ & & $100.0 \%$ & $0.51[0.05,5.72]$ \\
\hline Subtotal $(95 \% \mathrm{CI})$ & 99 & 102 & & $100.0 \%$ & $0.51[0.05,5.72]$ \\
\hline \multicolumn{6}{|c|}{ Total events: I (Extensive tests), 2 (Control) } \\
\hline \multicolumn{6}{|c|}{ Heterogeneity: not applicable } \\
\hline \multicolumn{6}{|c|}{ Test for overall effect: $Z=0.55(P=0.59)$} \\
\hline \multicolumn{6}{|l|}{ | | Prostate } \\
\hline Piccioli 2004b & 1/99 & $2 / 102$ & & $100.0 \%$ & $0.5 \mid[0.05,5.72]$ \\
\hline Subtotal $(95 \% \mathrm{CI})$ & 99 & 102 & & $100.0 \%$ & $0.51[0.05,5.72]$ \\
\hline \multicolumn{6}{|c|}{ Total events: I (Extensive tests), 2 (Control) } \\
\hline \multicolumn{6}{|c|}{ Heterogeneity: not applicable } \\
\hline \multicolumn{6}{|c|}{ Test for overall effect: $Z=0.55(P=0.59)$} \\
\hline \multicolumn{6}{|l|}{12 Pancreas } \\
\hline Piccioli 2004b & 0/99 & $2 / 102$ & & $100.0 \%$ & $0.20[0.01,4.26]$ \\
\hline Subtotal $(95 \% \mathrm{CI})$ & 99 & 102 & & $100.0 \%$ & $0.20[0.01,4.26]$ \\
\hline \multicolumn{6}{|c|}{ Total events: 0 (Extensive tests), 2 (Control) } \\
\hline \multicolumn{6}{|c|}{ Heterogeneity: not applicable } \\
\hline Test for overall effect: $Z=$ & $=0.30)$ & & & & \\
\hline
\end{tabular}

$\begin{array}{llllll}0.0010 .01 & 0.1 \quad \text { । } & 10 \quad 100 \quad 1000\end{array}$

Favours control Favours extensive tests

Effect of testing for cancer on cancer- and venous thromboembolism (VTE)-related mortality and morbidity in people with unprovoked 35 VTE (Review)

Copyright $\odot 2017$ The Cochrane Collaboration. Published by John Wiley \& Sons, Ltd. 


\section{Analysis I.3. Comparison I Extensive tests versus tests at the physician's discretion, Outcome 3 Characteristics of diagnosed cancer: stage of cancer.}

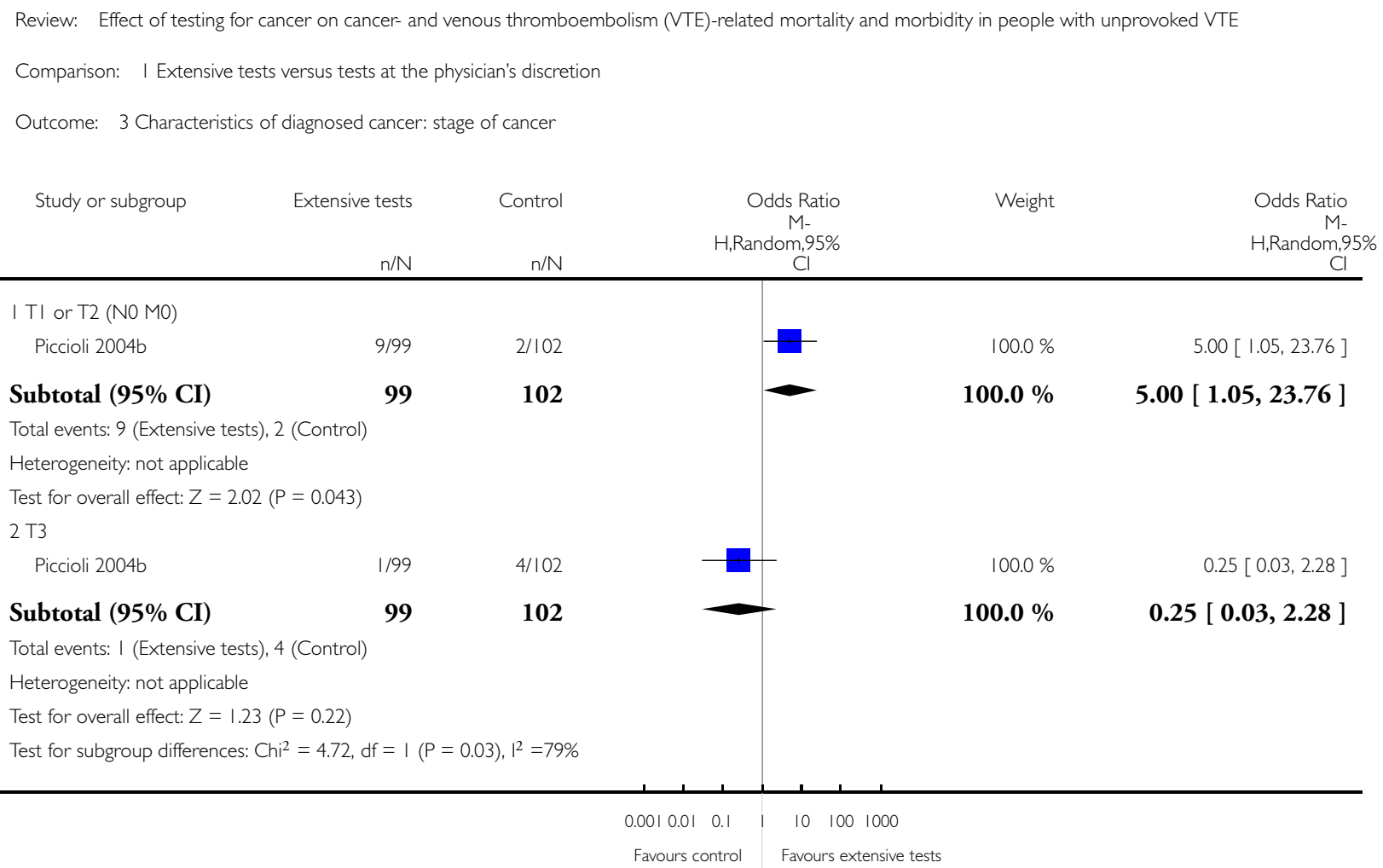

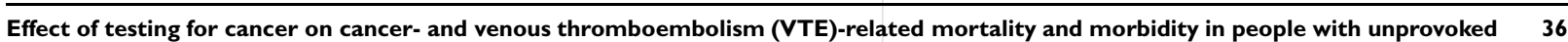
VTE (Review)

Copyright @ 2017 The Cochrane Collaboration. Published by John Wiley \& Sons, Ltd. 
Analysis I.4. Comparison I Extensive tests versus tests at the physician's discretion, Outcome 4 Frequency of underlying cancer diagnosis.

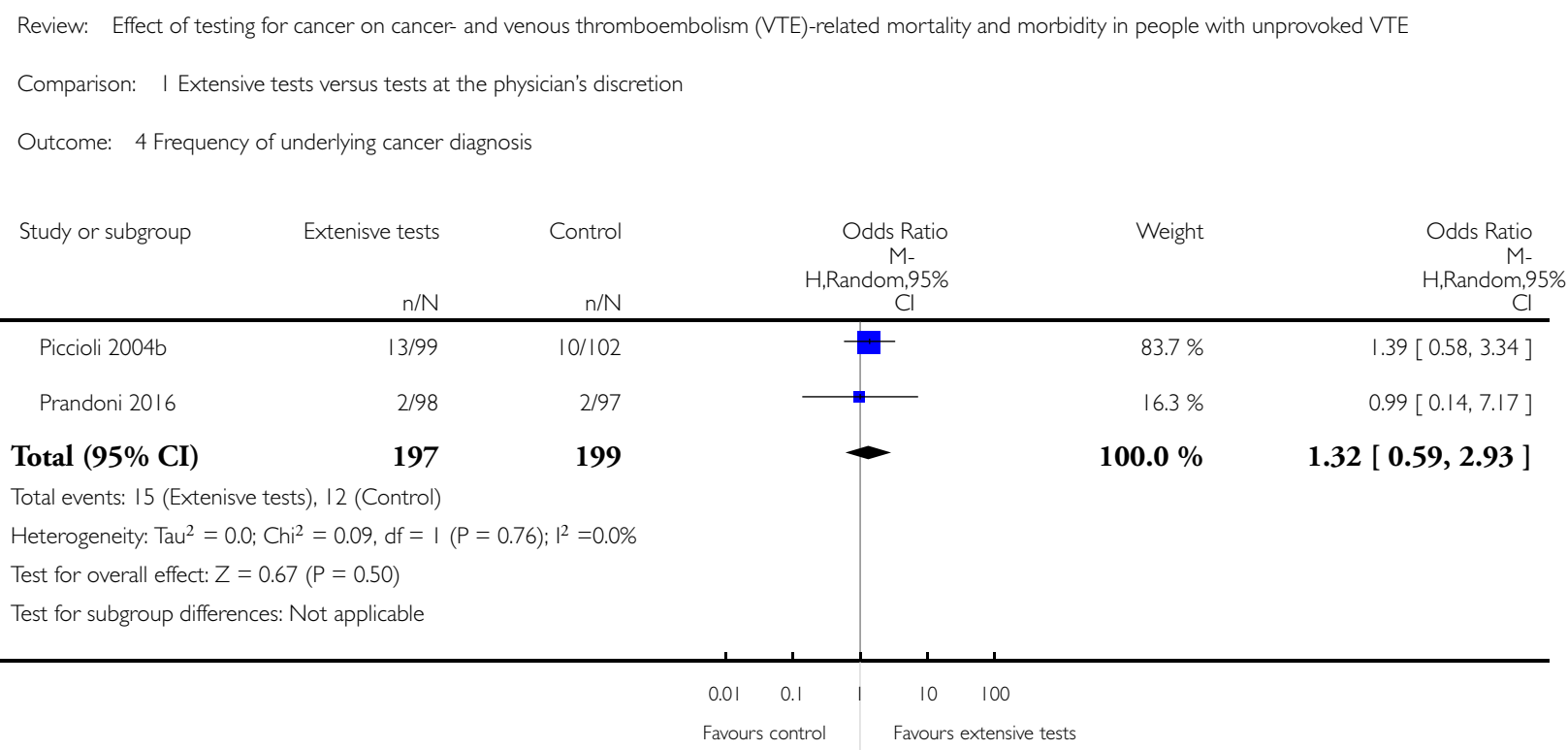

Effect of testing for cancer on cancer- and venous thromboembolism (VTE)-related mortality and morbidity in people with unprovoked 37 VTE (Review)

Copyright $\odot 2017$ The Cochrane Collaboration. Published by John Wiley \& Sons, Ltd. 


\section{Analysis 2.I. Comparison 2 Standard testing plus PET/CT scanning versus standard testing alone, Outcome}

I All-cause mortality.

Review: Effect of testing for cancer on cancer- and venous thromboembolism (VTE)-related mortality and morbidity in people with unprovoked VTE

Comparison: 2 Standard testing plus PET/CT scanning versus standard testing alone

Outcome: I All-cause mortality

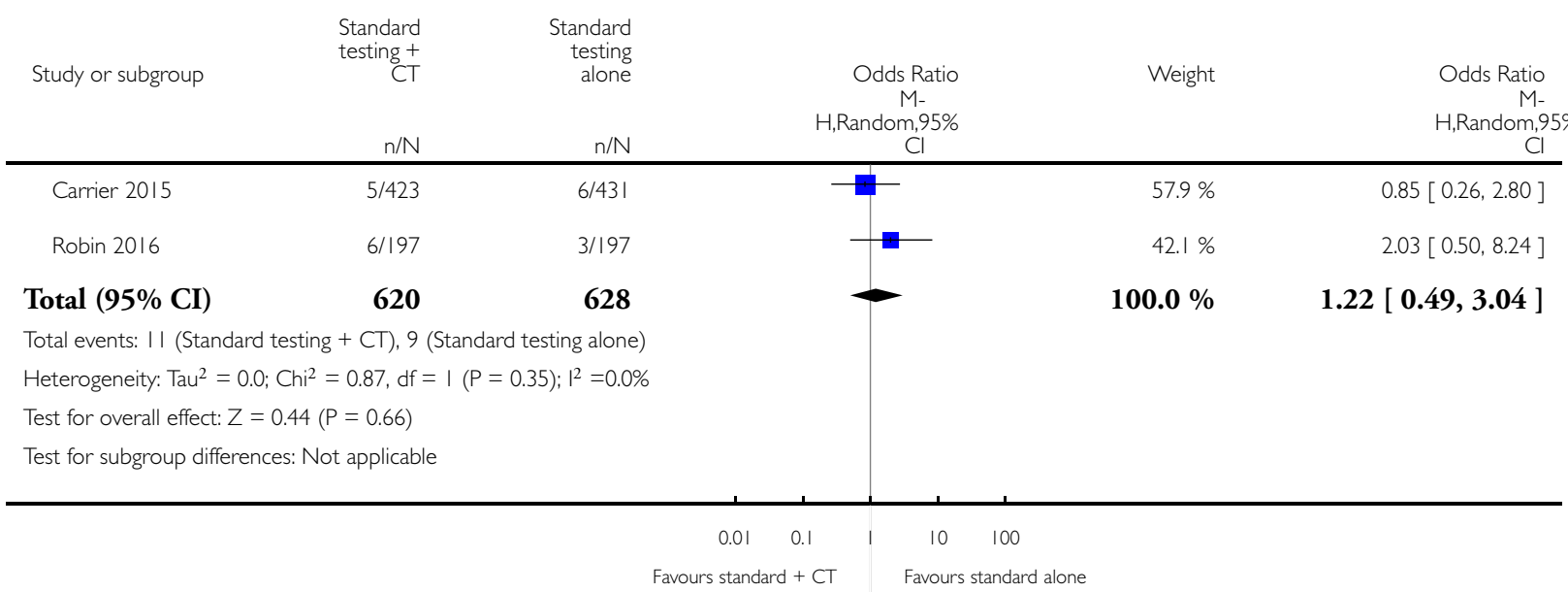

Effect of testing for cancer on cancer- and venous thromboembolism (VTE)-related mortality and morbidity in people with unprovoked 


\section{Analysis 2.2. Comparison 2 Standard testing plus PET/CT scanning versus standard testing alone, Outcome}

2 Cancer-related mortality.

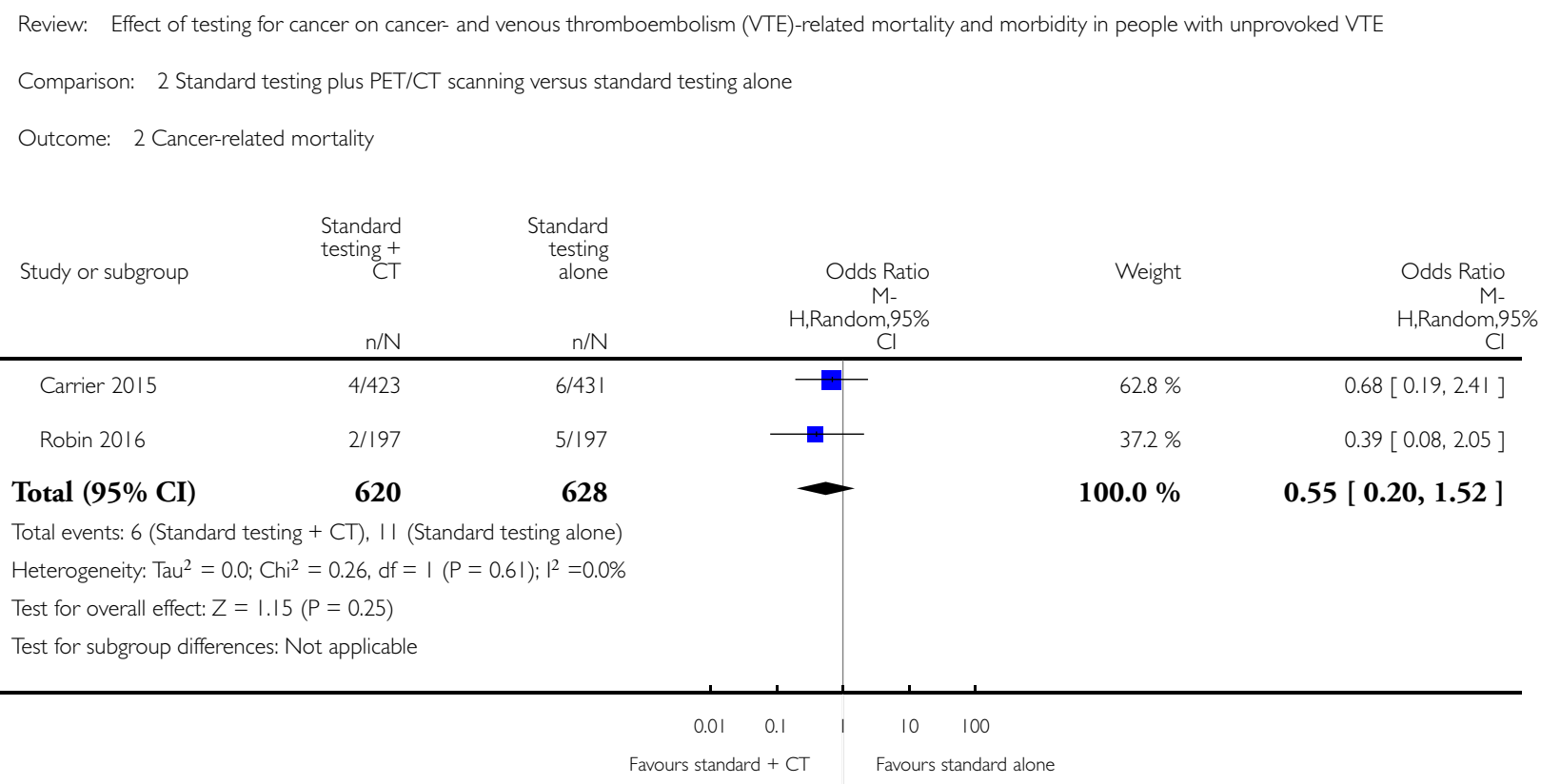




\section{Analysis 2.3. Comparison 2 Standard testing plus PET/CT scanning versus standard testing alone, Outcome} 3 Venous thromboembolism-related morbidity.

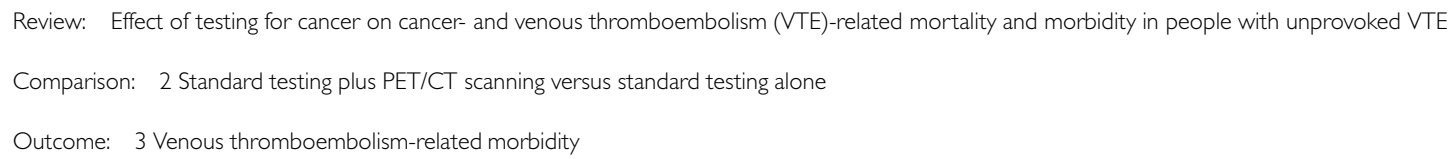

\begin{tabular}{|c|c|c|c|c|c|}
\hline Study or subgroup & $\begin{array}{r}\text { Standard } \\
\text { testing }+ \\
\text { CT }\end{array}$ & $\begin{array}{c}\text { Standard } \\
\text { testing } \\
\text { alone }\end{array}$ & $\begin{array}{r}\text { Odds Ratio } \\
\text { M- } \\
\text { H,Random,95\% } \\
\text { Cl }\end{array}$ & Weight & $\begin{array}{c}\text { Odds Ratio } \\
\text { M- } \\
\text { H,Random,95\% } \\
\text { Cl }\end{array}$ \\
\hline Carrier 2015 & | 4/423 & $|4 / 43|$ & & $100.0 \%$ & $1.02[0.48,2.17]$ \\
\hline Total (95\% CI) & 423 & 431 & - & $100.0 \%$ & $1.02[0.48,2.17]$ \\
\hline \multicolumn{6}{|c|}{ Total events: I 4 (Standard testing + CT), I4 (Standard testing alone) } \\
\hline \multicolumn{6}{|c|}{ Heterogeneity: not applicable } \\
\hline \multicolumn{6}{|c|}{ Test for overall effect: $Z=0.05(P=0.96)$} \\
\hline Test for subgroup diff & t applicable & & & & \\
\hline
\end{tabular}




\section{Analysis 2.4. Comparison 2 Standard testing plus PET/CT scanning versus standard testing alone, Outcome 4 Characteristics of diagnosed cancer: type of cancer.}

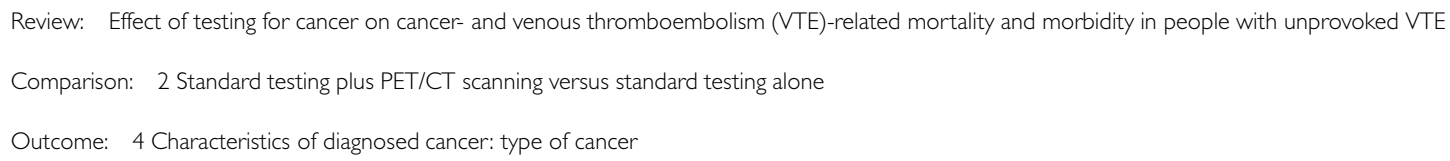




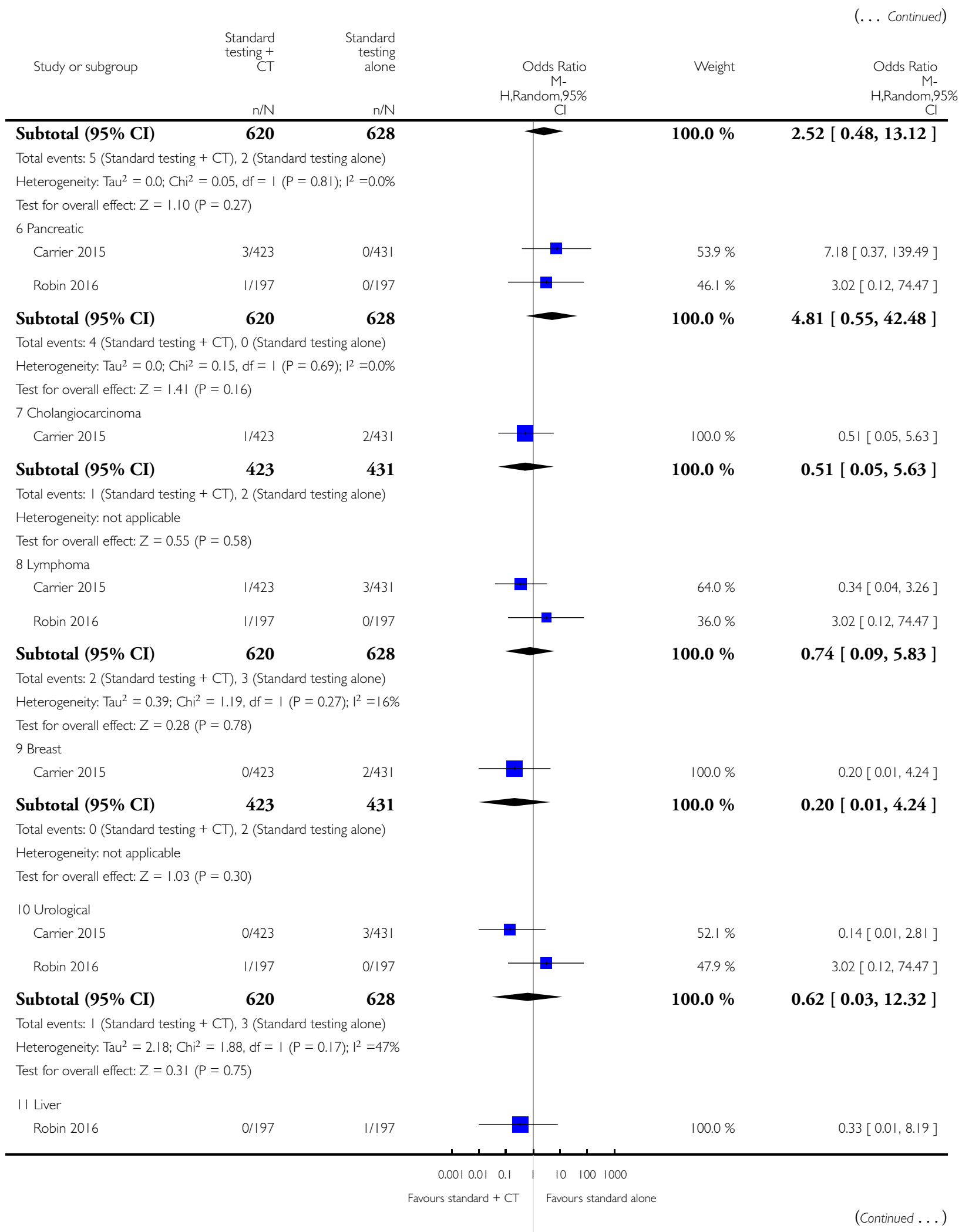

Effect of testing for cancer on cancer- and venous thromboembolism (VTE)-related mortality and morbidity in people with unprovoked 42 VTE (Review)

Copyright $\odot 2017$ The Cochrane Collaboration. Published by John Wiley \& Sons, Ltd. 


\begin{tabular}{|c|c|c|c|c|c|}
\hline Study or subgroup & $\begin{array}{r}\text { Standard } \\
\text { testing }+ \\
\text { CT }\end{array}$ & $\begin{array}{r}\text { Standard } \\
\text { testing } \\
\text { alone } \\
\\
\mathrm{n} / \mathrm{N} \\
\end{array}$ & $\begin{array}{r}\text { Odds Ratio } \\
\text { M- } \\
\text { H,Random,95\% } \\
\text { Cl }\end{array}$ & Weight & $\begin{array}{c}\text { Odds Ratio } \\
\text { M- } \\
\text { H,Random,95\% } \\
\text { Cl } \\
\end{array}$ \\
\hline Subtotal $(95 \% \mathrm{CI})$ & 197 & 197 & -1 & $100.0 \%$ & $0.33[0.01,8.19]$ \\
\hline \multicolumn{6}{|c|}{ Total events: 0 (Standard testing + CT), I (Standard testing alone) } \\
\hline \multicolumn{6}{|c|}{ Heterogeneity: not applicable } \\
\hline \multicolumn{6}{|c|}{ Test for overall effect: $Z=0.67(P=0.50)$} \\
\hline \multicolumn{6}{|l|}{12 Head and neck } \\
\hline Robin 2016 & 1/197 & 0/197 & & $100.0 \%$ & $3.02[0.12,74.47]$ \\
\hline Subtotal $(95 \% \mathrm{CI})$ & 197 & 197 & & $100.0 \%$ & $3.02[0.12,74.47]$ \\
\hline \multicolumn{6}{|c|}{ Total events: I (Standard testing + CT), 0 (Standard testing alone) } \\
\hline \multicolumn{6}{|c|}{ Heterogeneity: not applicable } \\
\hline \multicolumn{6}{|c|}{ Test for overall effect: $Z=0.67(P=0.50)$} \\
\hline \multicolumn{6}{|l|}{13 Lung } \\
\hline Robin 2016 & 1/197 & $0 / 197$ & - & $100.0 \%$ & $3.02[0.12,74.47]$ \\
\hline Subtotal $(95 \% \mathrm{CI})$ & 197 & 197 & & $100.0 \%$ & $3.02[0.12,74.47]$ \\
\hline \multicolumn{6}{|c|}{ Total events: I (Standard testing + CT), 0 (Standard testing alone) } \\
\hline \multicolumn{6}{|c|}{ Heterogeneity: not applicable } \\
\hline \multicolumn{6}{|c|}{ Test for overall effect: $Z=0.67(P=0.50)$} \\
\hline \multicolumn{6}{|l|}{14 Unknown primary } \\
\hline Carrier 2015 & 0/423 & $|/ 43|$ & & $100.0 \%$ & $0.34[0.01,8.34]$ \\
\hline Subtotal $(95 \% \mathrm{CI})$ & 423 & 431 & & $100.0 \%$ & $0.34[0.01,8.34]$ \\
\hline \multicolumn{6}{|c|}{ Total events: 0 (Standard testing + CT), I (Standard testing alone) } \\
\hline \multicolumn{6}{|c|}{ Heterogeneity: not applicable } \\
\hline \multicolumn{6}{|c|}{ Test for overall effect: $Z=0.66(P=0.5 \mathrm{I})$} \\
\hline Test for subgroup differen & $=8.44, \mathrm{df}=$ & $.81), I^{2}=0.0 \%$ & & & \\
\hline
\end{tabular}

Effect of testing for cancer on cancer- and venous thromboembolism (VTE)-related mortality and morbidity in people with unprovoked 


\section{Analysis 2.5. Comparison 2 Standard testing plus PET/CT scanning versus standard testing alone, Outcome}

5 Characteristics of diagnosed cancer: stage of cancer.

\begin{tabular}{|c|c|c|c|c|c|}
\hline \multicolumn{6}{|c|}{ Outcome: 5 Characteristics of diagnosed cancer: stage of cancer } \\
\hline Study or subgroup & $\begin{array}{r}\text { Standard } \\
\text { testing + } \\
\text { CT } \\
\\
\mathrm{n} / \mathrm{N} \\
\end{array}$ & $\begin{array}{r}\text { Standard } \\
\text { testing } \\
\text { alone } \\
\\
\mathrm{n} / \mathrm{N}\end{array}$ & $\begin{array}{r}\text { Odds Ratio } \\
\text { M- } \\
\text { H,Random, } 95 \% \\
\mathrm{Cl}\end{array}$ & Weight & $\begin{array}{c}\text { Odds Ratio } \\
\text { M- } \\
\text { H,Random,95\% } \\
\mathrm{Cl} \\
\end{array}$ \\
\hline \multicolumn{6}{|l|}{ | Early } \\
\hline Robin 2016 & $7 / 197$ & $4 / 197$ & + & $100.0 \%$ & $1.78[0.51,6.17]$ \\
\hline Subtotal $(95 \% \mathrm{CI})$ & 197 & 197 & - & $100.0 \%$ & $1.78[0.51,6.17]$ \\
\hline \multicolumn{6}{|c|}{ Total events: 7 (Standard testing + CT), 4 (Standard testing alone) } \\
\hline \multicolumn{6}{|c|}{ Heterogeneity: not applicable } \\
\hline \multicolumn{6}{|c|}{ Test for overall effect: $Z=0.91(P=0.37)$} \\
\hline \multicolumn{6}{|c|}{2 Advanced } \\
\hline Robin 2016 & 2/197 & 2/197 & & $100.0 \%$ & $1.00[0.14,7.17]$ \\
\hline Subtotal (95\% CI) & 197 & 197 & - & $100.0 \%$ & $1.00[0.14,7.17]$ \\
\hline \multicolumn{6}{|c|}{ Total events: 2 (Standard testing + CT), 2 (Standard testing alone) } \\
\hline \multicolumn{6}{|c|}{ Heterogeneity: not applicable } \\
\hline \multicolumn{6}{|c|}{ Test for overall effect: $Z=0.0(P=1.0)$} \\
\hline Test for subgroup differenc & $=0.23, \mathrm{df}=$ & 63), $\left.\right|^{2}=0.0 \%$ & & & \\
\hline
\end{tabular}




\section{Analysis 2.6. Comparison 2 Standard testing plus PET/CT scanning versus standard testing alone, Outcome}

6 Frequency of an underlying cancer diagnosis.

Review: Effect of testing for cancer on cancer- and venous thromboembolism (VTE)-related mortality and morbidity in people with unprovoked VTE

Comparison: 2 Standard testing plus PET/CT scanning versus standard testing alone

Outcome: 6 Frequency of an underlying cancer diagnosis

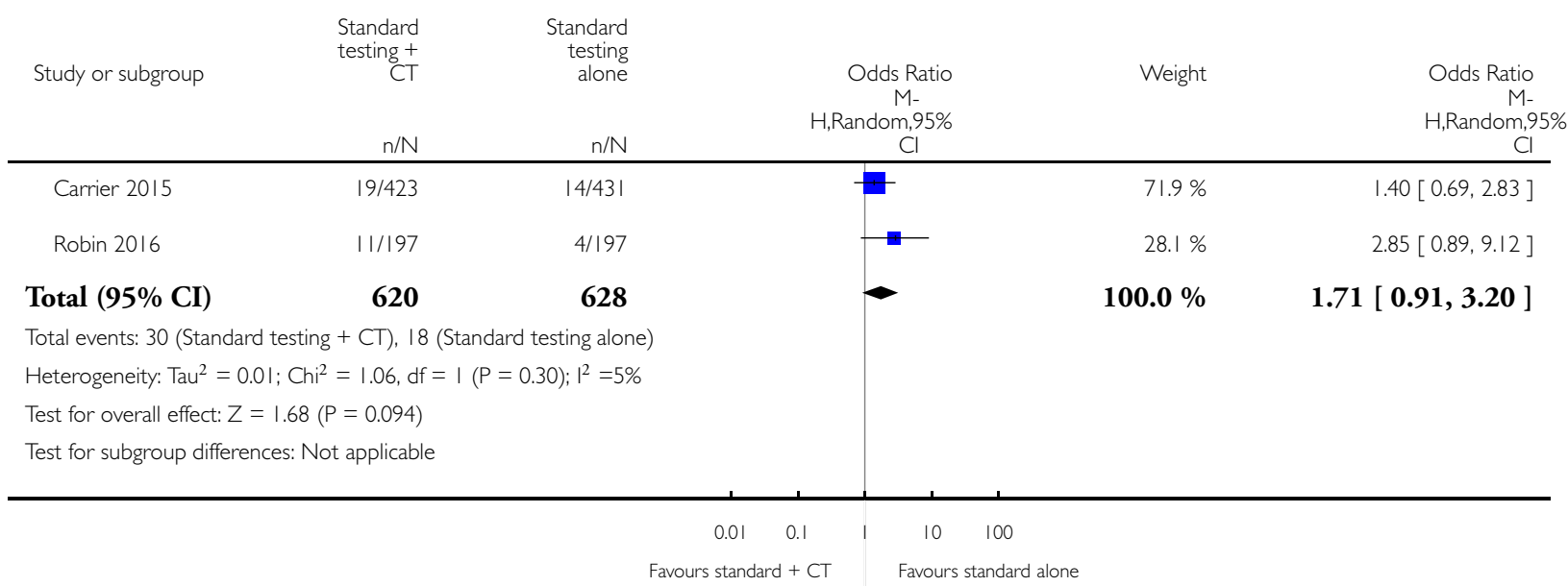

\section{A P PENDICES}

\section{Appendix I. Cochrane Register of Studies search strategy}

Search run on Thu Feb 162017

\begin{tabular}{l|l|l}
\hline$\# 1$ & MESH DESCRIPTOR Thrombosis & 1238 \\
\hline$\# 2$ & MESH DESCRIPTOR Thromboembolism & 899 \\
\hline$\# 3$ & $\begin{array}{l}\text { MESH DESCRIPTOR Venous Thromboem- } \\
\text { bolism }\end{array}$ & 242 \\
\hline$\# 4$ & $\begin{array}{l}\text { MESH DESCRIPTOR Venous Thrombosis } \\
\text { EXPLODE ALL TREES }\end{array}$ & 2005 \\
\hline
\end{tabular}

Effect of testing for cancer on cancer- and venous thromboembolism (VTE)-related mortality and morbidity in people with unprovoked 


\begin{tabular}{|c|c|c|}
\hline \#5 & $\begin{array}{l}\text { (thrombus* or thrombotic* or thrombolic* or } \\
\text { thromboemboli* or thrombos* or embol*):TI, } \\
\text { AB,KY }\end{array}$ & 17704 \\
\hline \#6 & $\begin{array}{l}\text { MESH DESCRIPTOR Pulmonary Embolism } \\
\text { EXPLODE ALL TREES }\end{array}$ & 735 \\
\hline$\# 7$ & (PE or DVT or VTE):TI,AB,KY & 4704 \\
\hline \#8 & $\left(\left(\right.\right.$ vein $^{*}$ or ven*) near thromb*):TI,AB,KY & 6380 \\
\hline$\# 9$ & (blood near3 clot*):TI,AB,KY & 2761 \\
\hline \#10 & (pulmonary near3 clot*):TI,AB,KY & 5 \\
\hline \#11 & (lung near3 clot*):TI,AB,KY & 4 \\
\hline \#12 & $\begin{array}{l}\# 1 \text { OR \#2 OR \#3 OR \#4 OR \#5 OR \#6 OR \# } \\
7 \text { OR \#8 OR \#9 OR \#10 OR \#11 }\end{array}$ & 23058 \\
\hline \#13 & $\begin{array}{l}\text { MESH DESCRIPTOR Neoplasms EXPLODE } \\
\text { ALL TREES }\end{array}$ & 47488 \\
\hline \#14 & malignan*:TI,AB,KY & 10083 \\
\hline \#15 & neoplas*:TI,AB,KY & 49421 \\
\hline \#16 & cancer*:TI,AB, KY & 72840 \\
\hline \#17 & (carcinoma* or adenocarcinoma*):TI,AB, KY & 24789 \\
\hline \#18 & (tumour* or tumor*):TI,AB,KY & 33693 \\
\hline \#19 & Trousseau:TI,AB,KY & 5 \\
\hline \#20 & $\begin{array}{l}\text { \#13 OR \#14 OR \#15 OR \#16 OR \#17 OR \# } \\
18 \text { OR \#19 }\end{array}$ & 110639 \\
\hline \#21 & $\begin{array}{l}\text { MESH DESCRIPTOR Mass Screening EX- } \\
\text { PLODE ALL TREES }\end{array}$ & 3152 \\
\hline$\# 22$ & $\begin{array}{l}\text { MESH DESCRIPTOR Early Diagnosis EX- } \\
\text { PLODE ALL TREES }\end{array}$ & 1070 \\
\hline$\# 23$ & screen*:TI,AB,KY & 25086 \\
\hline$\# 24$ & diagnos*:TI,AB,KY & 102899 \\
\hline \#25 & assess*:TI,AB,KY & 248330 \\
\hline
\end{tabular}

Effect of testing for cancer on cancer- and venous thromboembolism (VTE)-related mortality and morbidity in people with unprovoked 46 VTE (Review)

Copyright $\odot 2017$ The Cochrane Collaboration. Published by John Wiley \& Sons, Ltd. 


\begin{tabular}{l|l|l}
\hline$\# 26$ & investigat:TI,AB,KY & 128920 \\
\hline$\# 27$ & test:TI,AB,KY & 121160 \\
\hline$\# 28$ & testing:TI,AB,KY & 26669 \\
\hline$\# 29$ & \#21 OR \#22 OR \#23 OR \#24 OR \#25 OR \# & 445824 \\
\hline 26 OR \#27 OR \#28 & 2091 \\
\hline \#31 & \#12 AND \#20 AND \#29 & 160223 \\
\hline \#32 & NOT SR-PVD:CC AND 31/01/2015 TO & 760 \\
\hline
\end{tabular}

\section{Appendix 2. Trials registries searches}

WHO Registry

12 records for 11 trials found for: cancer and screen* and thromb*

6 records for 5 trials found for: neoplas* and screen* and thromb*

Clinicaltrials.gov

16 studies found for: cancer and screen* and thrombosis

16 studies found for: neoplasm and screen* and thrombosis

ISRCTN Registry

No results found for "cancer and screen* and thromb*"

No results found for "neoplasm and screen* and thromb*"

\section{Appendix 3. Extensive tests versus tests at the physician's discretion}

Extensive tests versus tests at the physician's discretion

Patient or population: people with unprovoked VTE

Setting: hospital

Intervention: extensive tests

Comparison: tests at physician's discretion

\begin{tabular}{|l|l|l|l|l|}
\hline Outcomes & $\begin{array}{l}\text { Anticipated absolute effects* }(95 \% \\
\text { CI })\end{array}$ & $\begin{array}{l}\text { Relative effect } \\
(95 \% \mathrm{CI})\end{array}$ & $\begin{array}{l}\text { No of partici- } \\
\text { pants } \\
\text { (studies) }\end{array}$ & $\begin{array}{l}\text { Quality of the Comments } \\
\text { evidence } \\
\text { (GRADE) }\end{array}$ \\
\hline & $\begin{array}{l}\text { Risk with tests } \\
\text { at physician's } \\
\text { discretion }\end{array}$ & $\begin{array}{l}\text { Rive tests } \\
\text { sivith exten- }\end{array}$ & \\
\hline
\end{tabular}




\begin{tabular}{|c|c|c|c|c|c|c|}
\hline \multirow{2}{*}{$\begin{array}{l}\text { Char- } \\
\text { acteristics of di- } \\
\text { agnosed cancer: } \\
\text { type of cancer - } \\
\text { lung }\end{array}$} & \multicolumn{2}{|c|}{ Study population } & \multirow{2}{*}{$\begin{array}{l}\text { OR } 2.08 \\
(0.19 \text { to } 23.34)\end{array}$} & \multirow{2}{*}{$\begin{array}{l}201 \\
(1 \mathrm{RCT})\end{array}$} & \multirow{2}{*}{$\begin{array}{l}\oplus \oplus \bigcirc \bigcirc \\
\mathbf{L o w}^{1}\end{array}$} & \multirow[t]{2}{*}{ - } \\
\hline & 10 per 1000 & $\begin{array}{l}20 \text { per } 1000 \\
(2 \text { to } 188)\end{array}$ & & & & \\
\hline \multirow{2}{*}{$\begin{array}{l}\text { Char- } \\
\text { acteristics of di- } \\
\text { agnosed cancer: } \\
\text { type of cancer - } \\
\text { bladder }\end{array}$} & \multicolumn{2}{|c|}{ Study population } & \multirow[t]{2}{*}{$\begin{array}{l}\text { OR } 2.08 \\
(0.19 \text { to } 23.34)\end{array}$} & \multirow{2}{*}{$\begin{array}{l}201 \\
(1 \mathrm{RCT})\end{array}$} & \multirow{2}{*}{$\begin{array}{l}\oplus \oplus \bigcirc \bigcirc \\
\mathbf{L o w}^{1}\end{array}$} & \multirow[t]{2}{*}{ - } \\
\hline & 10 per 1000 & $\begin{array}{l}20 \text { per } 1000 \\
\text { ( } 2 \text { to } 188)\end{array}$ & & & & \\
\hline \multirow{2}{*}{$\begin{array}{l}\text { Char- } \\
\text { acteristics of di- } \\
\text { agnosed cancer: } \\
\text { type of cancer - } \\
\text { stomach }\end{array}$} & \multicolumn{2}{|c|}{ Study population } & \multirow[t]{2}{*}{$\begin{array}{l}\text { OR } 1.03 \\
(0.06 \text { to } 16.71)\end{array}$} & \multirow[t]{2}{*}{$\begin{array}{l}201 \\
(1 \mathrm{RCT})\end{array}$} & \multirow[t]{2}{*}{$\begin{array}{l}\oplus \oplus \bigcirc \bigcirc \\
\text { Low }^{1}\end{array}$} & \multirow[t]{2}{*}{ - } \\
\hline & 10 per 1000 & $\begin{array}{l}10 \text { per } 1000 \\
\text { (1 to } 142)\end{array}$ & & & & \\
\hline \multirow{2}{*}{$\begin{array}{l}\text { Char- } \\
\text { acteristics of di- } \\
\text { agnosed cancer: } \\
\text { type of cancer - } \\
\text { kidney }\end{array}$} & \multicolumn{2}{|c|}{ Study population } & \multirow[t]{2}{*}{$\begin{array}{l}\text { OR } 3.12 \\
(0.13 \text { to } 77.55)\end{array}$} & \multirow[t]{2}{*}{$\begin{array}{l}201 \\
(1 \mathrm{RCT})\end{array}$} & \multirow[t]{2}{*}{$\begin{array}{l}\oplus \oplus \bigcirc \bigcirc \\
\text { Low }^{1}\end{array}$} & \multirow[t]{2}{*}{ - } \\
\hline & 0 per 1000 & $\begin{array}{l}0 \text { per } 1000 \\
(0 \text { to } 0)\end{array}$ & & & & \\
\hline \multirow{2}{*}{$\begin{array}{l}\text { Char- } \\
\text { acteristics of di- } \\
\text { agnosed cancer: } \\
\text { type of cancer - } \\
\text { adrenal gland }\end{array}$} & \multicolumn{2}{|c|}{ Study population } & \multirow[t]{2}{*}{$\begin{array}{l}\text { OR } 3.12 \\
(0.13 \text { to } 77.55)\end{array}$} & \multirow[t]{2}{*}{$\begin{array}{l}201 \\
(1 \mathrm{RCT})\end{array}$} & \multirow[t]{2}{*}{$\begin{array}{l}\oplus \oplus \bigcirc \bigcirc \\
\mathbf{L o w}^{1}\end{array}$} & - \\
\hline & 0 per 1000 & $\begin{array}{l}0 \text { per } 1000 \\
(0 \text { to } 0)\end{array}$ & & & & \\
\hline \multirow{2}{*}{$\begin{array}{l}\text { Char- } \\
\text { acteristics of di- } \\
\text { agnosed cancer: } \\
\text { type of cancer - } \\
\text { liver }\end{array}$} & \multicolumn{2}{|c|}{ Study population } & \multirow[t]{2}{*}{$\begin{array}{l}\text { OR } 3.12 \\
(0.13 \text { to } 77.55)\end{array}$} & \multirow[t]{2}{*}{$\begin{array}{l}201 \\
(1 \mathrm{RCT})\end{array}$} & \multirow[t]{2}{*}{$\begin{array}{l}\oplus \oplus \bigcirc \bigcirc \\
\text { Low }^{1}\end{array}$} & - \\
\hline & 0 per 1000 & $\begin{array}{l}0 \text { per } 1000 \\
(0 \text { to } 0)\end{array}$ & & & & \\
\hline \multirow{2}{*}{$\begin{array}{l}\text { Char- } \\
\text { acteristics of di- } \\
\text { agnosed cancer: } \\
\text { type of cancer - } \\
\text { uterus }\end{array}$} & \multicolumn{2}{|c|}{ Study population } & \multirow[t]{2}{*}{$\begin{array}{l}\text { OR } 3.12 \\
(0.13 \text { to } 77.55)\end{array}$} & \multirow[t]{2}{*}{$\begin{array}{l}201 \\
(1 \mathrm{RCT})\end{array}$} & $\begin{array}{l}\oplus \oplus \bigcirc \bigcirc \\
\text { Low }^{1}\end{array}$ & - \\
\hline & 0 per 1000 & $\begin{array}{l}0 \text { per } 1000 \\
(0 \text { to } 0)\end{array}$ & & & & \\
\hline $\begin{array}{l}\text { Char- } \\
\text { acteristics of di- }\end{array}$ & Study popul & & $\begin{array}{l}\text { OR } 1.03 \\
(0.06 \text { to } 16.71)\end{array}$ & $\begin{array}{l}201 \\
(1 \mathrm{RCT})\end{array}$ & $\begin{array}{l}\oplus \oplus \bigcirc \bigcirc \\
\text { Low }^{1}\end{array}$ & - \\
\hline $\begin{array}{l}\text { type of cancer - } \\
\text { breast }\end{array}$ & 10 per 1000 & $\begin{array}{l}10 \text { per } 1000 \\
(1 \text { to } 142)\end{array}$ & & & & \\
\hline
\end{tabular}




\begin{tabular}{|c|c|c|c|c|c|c|}
\hline \multirow{2}{*}{$\begin{array}{l}\text { Char- } \\
\text { acteristics of di- } \\
\text { agnosed cancer: } \\
\text { type of cancer - } \\
\text { ovary }\end{array}$} & \multicolumn{2}{|c|}{ Study population } & \multirow{2}{*}{$\begin{array}{l}\text { OR } 3.12 \\
(0.13 \text { to } 77.55)\end{array}$} & \multirow{2}{*}{$\begin{array}{l}201 \\
(1 \mathrm{RCT})\end{array}$} & \multirow{2}{*}{$\begin{array}{l}\oplus \oplus \bigcirc \bigcirc \\
\mathbf{L o w}^{1}\end{array}$} & \multirow[t]{2}{*}{ - } \\
\hline & 0 per 1000 & $\begin{array}{l}0 \text { per } 1000 \\
(0 \text { to } 0)\end{array}$ & & & & \\
\hline \multirow{2}{*}{$\begin{array}{l}\text { Char- } \\
\text { acteristics of di- } \\
\text { agnosed cancer: } \\
\text { type of cancer - } \\
\text { colon }\end{array}$} & \multicolumn{2}{|c|}{ Study population } & \multirow[t]{2}{*}{$\begin{array}{l}\text { OR } 0.51 \\
(0.05 \text { to } 5.72)\end{array}$} & \multirow[t]{2}{*}{$\begin{array}{l}201 \\
(1 \mathrm{RCT})\end{array}$} & \multirow[t]{2}{*}{$\begin{array}{l}\oplus \oplus \bigcirc \bigcirc \\
\text { Low }^{1}\end{array}$} & \multirow[t]{2}{*}{-} \\
\hline & 20 per 1000 & $\begin{array}{l}10 \text { per } 1000 \\
(1 \text { to } 103)\end{array}$ & & & & \\
\hline \multirow{2}{*}{$\begin{array}{l}\text { Char- } \\
\text { acteristics of di- } \\
\text { agnosed cancer: } \\
\text { type of cancer - } \\
\text { prostate }\end{array}$} & \multicolumn{2}{|c|}{ Study population } & \multirow[t]{2}{*}{$\begin{array}{l}\text { OR } 0.51 \\
(0.05 \text { to } 5.72)\end{array}$} & \multirow[t]{2}{*}{$\begin{array}{l}201 \\
(1 \mathrm{RCT})\end{array}$} & \multirow[t]{2}{*}{$\begin{array}{l}\oplus \oplus \bigcirc \bigcirc \\
\text { Low }^{1}\end{array}$} & \multirow[t]{2}{*}{-} \\
\hline & 20 per 1000 & $\begin{array}{l}10 \text { per } 1000 \\
(1 \text { to } 103)\end{array}$ & & & & \\
\hline \multirow{2}{*}{$\begin{array}{l}\text { Char- } \\
\text { acteristics of di- } \\
\text { agnosed cancer: } \\
\text { type of cancer - } \\
\text { pancreas }\end{array}$} & \multicolumn{2}{|c|}{ Study population } & \multirow[t]{2}{*}{$\begin{array}{l}\text { OR } 0.20 \\
(0.01 \text { to } 4.26)\end{array}$} & \multirow[t]{2}{*}{$\begin{array}{l}201 \\
(1 \mathrm{RCT})\end{array}$} & \multirow[t]{2}{*}{$\begin{array}{l}\oplus \oplus \bigcirc \bigcirc \\
\text { Low }^{1}\end{array}$} & \multirow[t]{2}{*}{ - } \\
\hline & 20 per 1000 & $\begin{array}{l}4 \text { per } 1000 \\
(0 \text { to } 79)\end{array}$ & & & & \\
\hline
\end{tabular}

*The risk in the intervention group (and its $95 \%$ confidence interval) is based on the assumed risk in the comparison group and the relative effect of the intervention (and its $95 \% \mathrm{CI}$ ).

CI: confidence interval; OR: odds ratio; RCT: randomised controlled trial; VTE: venous thromboembolism.

\section{GRADE Working Group grades of evidence}

High quality: We are very confident that the true effect lies close to that of the estimate of the effect.

Moderate quality: We are moderately confident in the effect estimate: The true effect is likely to be close to the estimate of the effect, but there is a possibility that it is substantially different.

Low quality: Our confidence in the effect estimate is limited: The true effect may be substantially different from the estimate of the effect.

Very low quality: We have very little confidence in the effect estimate: The true effect is likely to be substantially different from the estimate of effect

${ }^{1}$ Quality of evidence downgraded for imprecision due to low number of events. Downgraded further as risk of bias high in study by Piccioli 2004b. Study terminated early after inclusion of only 201 participants after 5 years for several reasons. First, only five of more than 40 potential participating centres could contribute participants to study. Second, some medical ethics committees rejected the protocol because of absence of screening for occult cancer in the control group, other centres could not start because the proposed extensive screening was judged unethical. Finally, identification of cancer at an apparent early stage in extensive screening group led to an increasing tendency among physicians in participating hospitals to initiate screening for cancer in control participants.

Effect of testing for cancer on cancer- and venous thromboembolism (VTE)-related mortality and morbidity in people with unprovoked 


\section{Appendix 4. Standard testing plus PET/CT scanning versus standard testing alone}

Standard testing plus PET/CT scanning versus standard testing alone

Patient or population: people with unprovoked VTE

Setting: hospital

Intervention: standard testing + PET/CT scanning

Comparison: standard testing alone

\begin{tabular}{|c|c|c|c|c|c|c|}
\hline \multirow[t]{2}{*}{ Outcomes } & \multicolumn{2}{|c|}{$\begin{array}{l}\text { Anticipated absolute effects* }{ }^{*}(95 \% \\
\text { CI) }\end{array}$} & \multirow[t]{2}{*}{$\begin{array}{l}\text { Relative effect } \\
(95 \% \mathrm{CI})\end{array}$} & \multirow{2}{*}{$\begin{array}{l}\text { No of partici- } \\
\text { pants } \\
\text { (studies) }\end{array}$} & \multirow{2}{*}{$\begin{array}{l}\text { Quality of the } \\
\text { evidence } \\
\text { (GRADE) }\end{array}$} & \multirow[t]{2}{*}{ Comments } \\
\hline & $\begin{array}{l}\text { Risk with } \\
\text { standard testing } \\
\text { alone }\end{array}$ & $\begin{array}{l}\text { Risk with stan- } \\
\text { dard testing + } \\
\text { PET/CT scan- } \\
\text { ning }\end{array}$ & & & & \\
\hline \multirow{2}{*}{$\begin{array}{l}\text { Char- } \\
\text { acteristics of di- } \\
\text { agnosed cancer: } \\
\text { type of cancer - } \\
\text { acute leukaemia }\end{array}$} & \multicolumn{2}{|l|}{ Study population } & \multirow[t]{2}{*}{$\begin{array}{l}\text { OR } 1.62 \\
(0.20 \text { to } 13.22)\end{array}$} & \multirow[t]{2}{*}{$\begin{array}{l}1248 \\
(2 \text { RCTs })\end{array}$} & \multirow[t]{2}{*}{$\begin{array}{l}\oplus \oplus \bigcirc \bigcirc \\
\text { Low }\end{array}$} & \multirow[t]{2}{*}{ - } \\
\hline & 2 per 1000 & $\begin{array}{l}3 \text { per } 1000 \\
(0 \text { to } 21)\end{array}$ & & & & \\
\hline \multirow{2}{*}{$\begin{array}{l}\text { Char- } \\
\text { acteristics of di- } \\
\text { agnosed cancer: } \\
\text { type of cancer - } \\
\text { gynaecological }\end{array}$} & \multicolumn{2}{|l|}{ Study population } & \multirow{2}{*}{$\begin{array}{l}\text { OR } 2.39 \\
(0.43 \text { to } 13.36)\end{array}$} & \multirow{2}{*}{$\begin{array}{l}1248 \\
(2 \text { RCTs })\end{array}$} & \multirow{2}{*}{$\begin{array}{l}\oplus \oplus \bigcirc \bigcirc \\
\text { Low }\end{array}$} & \multirow[t]{2}{*}{-} \\
\hline & 3 per 1000 & $\begin{array}{l}8 \text { per } 1000 \\
(1 \text { to } 41)\end{array}$ & & & & \\
\hline \multirow{2}{*}{$\begin{array}{l}\text { Char- } \\
\text { acteristics of di- } \\
\text { agnosed cancer: } \\
\text { type of cancer - } \\
\text { skin: melanoma }\end{array}$} & \multicolumn{2}{|l|}{ Study population } & \multirow[t]{2}{*}{$\begin{array}{l}\text { OR } 1.02 \\
(0.06 \text { to } 16.34)\end{array}$} & \multirow[t]{2}{*}{$\begin{array}{l}854 \\
(1 \mathrm{RCT})\end{array}$} & \multirow[t]{2}{*}{$\begin{array}{l}\oplus \oplus \oplus \bigcirc \\
\text { Moderate }^{2}\end{array}$} & \multirow[t]{2}{*}{ - } \\
\hline & 2 per 1000 & $\begin{array}{l}2 \text { per } 1000 \\
(0 \text { to } 37)\end{array}$ & & & & \\
\hline \multirow{2}{*}{$\begin{array}{l}\text { Char- } \\
\text { acteristics of di- } \\
\text { agnosed cancer: } \\
\text { type of cancer - } \\
\text { colorectal }\end{array}$} & \multicolumn{2}{|l|}{ Study population } & \multirow{2}{*}{$\begin{array}{l}\text { OR } 0.43 \\
(0.08 \text { to } 2.40)\end{array}$} & \multirow{2}{*}{$\begin{array}{l}1248 \\
(2 \text { RCTs })\end{array}$} & \multirow{2}{*}{$\begin{array}{l}\oplus \oplus \bigcirc \bigcirc \\
\text { Low }\end{array}$} & \multirow[t]{2}{*}{ - } \\
\hline & 8 per 1000 & $\begin{array}{l}3 \text { per } 1000 \\
(1 \text { to } 19)\end{array}$ & & & & \\
\hline \multirow{2}{*}{$\begin{array}{l}\text { Char- } \\
\text { acteristics of di- } \\
\text { agnosed cancer: } \\
\text { type of cancer - } \\
\text { prostate }\end{array}$} & \multicolumn{2}{|l|}{ Study population } & \multirow[t]{2}{*}{$\begin{array}{l}\text { OR } 2.52 \\
(0.48 \text { to } 13.12)\end{array}$} & \multirow[t]{2}{*}{$\begin{array}{l}1248 \\
(2 \mathrm{RCTs})\end{array}$} & \multirow[t]{2}{*}{$\begin{array}{l}\oplus \oplus \bigcirc \bigcirc \\
\text { Low }\end{array}$} & \multirow[t]{2}{*}{ - } \\
\hline & 3 per 1000 & $\begin{array}{l}8 \text { per } 1000 \\
(2 \text { to } 40)\end{array}$ & & & & \\
\hline $\begin{array}{l}\text { Char- } \\
\text { acteristics of di- }\end{array}$ & Study population & & $\begin{array}{l}\text { OR } 4.81 \\
(0.55 \text { to } 42.48)\end{array}$ & $\begin{array}{l}1248 \\
(2 \text { RCTs) }\end{array}$ & $\begin{array}{l}\oplus \oplus \bigcirc \bigcirc \\
\text { Low }\end{array}$ & - \\
\hline
\end{tabular}


(Continued)

agnosed cancer:

type of cancer -

pancreatic

\begin{tabular}{ll}
\hline per 1000 & 0 per 1000 \\
$(0$ to 0$)$
\end{tabular}

(0 to 0$)$

\begin{tabular}{|c|c|c|c|c|c|c|}
\hline \multirow{2}{*}{$\begin{array}{l}\text { Char- } \\
\text { acteristics of di- } \\
\text { agnosed cancer: } \\
\text { type of cancer } \\
\text { - cholangiocar- } \\
\text { cinoma }\end{array}$} & \multicolumn{2}{|l|}{ Study population } & \multirow{2}{*}{$\begin{array}{l}\text { OR } 0.51 \\
(0.05 \text { to } 5.63)\end{array}$} & \multirow{2}{*}{$\begin{array}{l}854 \\
(1 \mathrm{RCT})\end{array}$} & \multirow{2}{*}{$\begin{array}{l}\oplus \oplus \oplus \bigcirc \\
\text { Moderate }^{2}\end{array}$} & \multirow[t]{2}{*}{-} \\
\hline & 5 per 1000 & $\begin{array}{l}2 \text { per } 1000 \\
(0 \text { to } 26)\end{array}$ & & & & \\
\hline \multirow{2}{*}{$\begin{array}{l}\text { Char- } \\
\text { acteristics of di- } \\
\text { agnosed cancer: } \\
\text { type of cancer - } \\
\text { lymphoma }\end{array}$} & \multicolumn{2}{|l|}{ Study population } & $\begin{array}{l}\text { OR } 0.74 \\
(0.09 \text { to } 5.83)\end{array}$ & $\begin{array}{l}1248 \\
\text { (2 RCTs) }\end{array}$ & $\begin{array}{l}\oplus \oplus \bigcirc \bigcirc \\
\text { Low } \\
1,2\end{array}$ & - \\
\hline & 5 per 1000 & $\begin{array}{l}4 \text { per } 1000 \\
(0 \text { to } 27)\end{array}$ & & & & \\
\hline \multirow{2}{*}{$\begin{array}{l}\text { Char- } \\
\text { acteristics of di- } \\
\text { agnosed cancer: } \\
\text { type of cancer - } \\
\text { breast }\end{array}$} & \multicolumn{2}{|l|}{ Study population } & $\begin{array}{l}\text { OR } 0.20 \\
(0.01 \text { to } 4.24)\end{array}$ & $\begin{array}{l}854 \\
(1 \mathrm{RCT})\end{array}$ & $\begin{array}{l}\oplus \oplus \oplus \bigcirc \\
\text { Moderate }^{2}\end{array}$ & - \\
\hline & 5 per 1000 & $\begin{array}{l}1 \text { per } 1000 \\
(0 \text { to } 19)\end{array}$ & & & & \\
\hline \multirow{2}{*}{$\begin{array}{l}\text { Char- } \\
\text { acteristics of di- } \\
\text { agnosed cancer: } \\
\text { type of cancer - } \\
\text { urological }\end{array}$} & \multicolumn{2}{|l|}{ Study population } & $\begin{array}{l}\text { OR } 0.62 \\
(0.03 \text { to } 12.32)\end{array}$ & $\begin{array}{l}1248 \\
\text { (2 RCTs) }\end{array}$ & $\begin{array}{l}\oplus \oplus \bigcirc \bigcirc \\
\text { Low } 1,2\end{array}$ & - \\
\hline & 5 per 1000 & $\begin{array}{l}3 \text { per } 1000 \\
(0 \text { to } 56)\end{array}$ & & & & \\
\hline \multirow{2}{*}{$\begin{array}{l}\text { Char- } \\
\text { acteristics of di- } \\
\text { agnosed cancer: } \\
\text { type of cancer - } \\
\text { liver }\end{array}$} & \multicolumn{2}{|l|}{ Study population } & $\begin{array}{l}\text { OR } 0.33 \\
(0.01 \text { to } 8.19)\end{array}$ & $\begin{array}{l}394 \\
(1 \mathrm{RCT})\end{array}$ & $\begin{array}{l}\oplus \oplus \bigcirc \bigcirc \\
\text { Low }^{1,2}\end{array}$ & - \\
\hline & 5 per 1000 & $\begin{array}{l}2 \text { per } 1000 \\
(0 \text { to } 40)\end{array}$ & & & & \\
\hline \multirow{2}{*}{$\begin{array}{l}\text { Char- } \\
\text { acteristics of di- } \\
\text { agnosed cancer: } \\
\text { type of cancer - } \\
\text { head and neck }\end{array}$} & \multicolumn{2}{|l|}{ Study population } & $\begin{array}{l}\text { OR } 3.02 \\
\text { (0.12 to } 74.47)\end{array}$ & $\begin{array}{l}394 \\
(1 \mathrm{RCT})\end{array}$ & $\begin{array}{l}\oplus \oplus \bigcirc \bigcirc \\
\text { Low }{ }^{1,2}\end{array}$ & - \\
\hline & 0 per 1000 & $\begin{array}{l}0 \text { per } 1000 \\
(0 \text { to } 0)\end{array}$ & & & & \\
\hline $\begin{array}{l}\text { Char- } \\
\text { acteristics of di- } \\
\text { agnosed cancer: } \\
\text { type of cancer - } \\
\text { lung }\end{array}$ & \multicolumn{2}{|l|}{ Study population } & $\begin{array}{l}\text { OR } 3.02 \\
(0.12 \text { to } 74.47)\end{array}$ & $\begin{array}{l}394 \\
(1 \mathrm{RCT})\end{array}$ & $\begin{array}{l}\oplus \oplus \bigcirc \bigcirc \\
\text { Low }^{1,2}\end{array}$ & - \\
\hline
\end{tabular}

Effect of testing for cancer on cancer- and venous thromboembolism (VTE)-related mortality and morbidity in people with unprovoked 5 VTE (Review)

Copyright @ 2017 The Cochrane Collaboration. Published by John Wiley \& Sons, Ltd. 


\begin{tabular}{|c|c|c|c|c|c|c|}
\hline & 0 per 1000 & $\begin{array}{l}0 \text { per } 1000 \\
(0 \text { to } 0)\end{array}$ & & & & \\
\hline \multirow{2}{*}{$\begin{array}{l}\text { Char- } \\
\text { acteristics of di- } \\
\text { agnosed cancer: } \\
\text { type of cancer } \\
\text { - unknown pri- } \\
\text { mary }\end{array}$} & \multicolumn{2}{|c|}{ Study population } & \multirow[t]{2}{*}{$\begin{array}{l}\text { OR } 0.34 \text { ( } 0.01 \text { to } \\
8.34)\end{array}$} & \multirow[t]{2}{*}{$\begin{array}{l}854 \\
(1 \mathrm{RCT})\end{array}$} & \multirow[t]{2}{*}{$\begin{array}{l}\oplus \oplus \oplus \bigcirc \\
\text { Moderate }^{2}\end{array}$} & \multirow[t]{2}{*}{-} \\
\hline & 5 per 1000 & $\begin{array}{l}8 \text { per } 1000 \\
(1 \text { to } 41)\end{array}$ & & & & \\
\hline
\end{tabular}

*The risk in the intervention group (and its $95 \%$ confidence interval) is based on the assumed risk in the comparison group and the relative effect of the intervention (and its 95\% CI).

CI: confidence interval; OR: odds ratio; PET/CT: positron emission tomography/computed tomography;RCT: randomised controlled trial; VTE: venous thromboembolism.

GRADE Working Group grades of evidence

High quality: We are very confident that the true effect lies close to that of the estimate of the effect.

Moderate quality: We are moderately confident in the effect estimate: The true effect is likely to be close to the estimate of the effect, but there is a possibility that it is substantially different.

Low quality: Our confidence in the effect estimate is limited: The true effect may be substantially different from the estimate of the effect.

Very low quality: We have very little confidence in the effect estimate: The true effect is likely to be substantially different from the estimate of effect

${ }^{1}$ Quality of evidence downgraded as risk of detection bias high for one study as outcome assessors not blinded to treatment (Robin 2016).

${ }^{2}$ Quality of evidence downgraded for imprecision due to low number of events.

\section{WHAT'S NEW}

Last assessed as up-to-date: 16 February 2017.

\begin{tabular}{|c|c|c|}
\hline Date & Event & Description \\
\hline 6 November 2017 & Amended & $\begin{array}{l}\text { Error in assumed control risk for outcome cancer-related mortality in Summary of findings table } \\
\text { 'Extensive tests versus tests at the physician's discretion' corrected and inconsistencies between } \\
\text { quality of evidence reported in text and Summary of findings table corrected }\end{array}$ \\
\hline
\end{tabular}

Effect of testing for cancer on cancer- and venous thromboembolism (VTE)-related mortality and morbidity in people with unprovoked 


\section{H I S T O R Y}

Protocol first published: Issue 11, 2013

Review first published: Issue 2, 2015

\begin{tabular}{lll}
\hline Date & Event & Description \\
\hline 20 July 2017 & New search has been performed & Searches rerun, two new included studies added \\
\hline 20 July 2017 & New citation required but conclusions have not changed & $\begin{array}{l}\text { Searches rerun, two new included studies added, Sum- } \\
\text { mary of Findings table added. No change to conclusions }\end{array}$ \\
\hline
\end{tabular}

\section{CONTRIBUTIONSOFAUTHORS}

LR: drafted the protocol, selected studies for inclusion, assessed the quality of studies, carried out data extraction, performed data analysis and wrote the review.

SEY: selected studies for inclusion, assessed the quality of the studies and carried out data extraction.

GS: provided clinical input into the review.

RA: contributed to the protocol and provided clinical input into the review.

\section{DECLARATIONSOF INTEREST}

LR: none known.

SEY: none known.

GS: none known.

RA: none known.

\section{SOURCES OF SUPPORT}

\section{Internal sources}

- No sources of support supplied 


\section{External sources}

- Chief Scientist Office, Scottish Government Health Directorates, The Scottish Government, UK.

The Cochrane Vascular editorial base is supported by the Chief Scientist Office.

\section{DIFFERENCESBETWEEN PROTOCOLANDREVIEW}

The primary outcome 'Non-cancer-related mortality (death due to some cause other than cancer or cancer-related treatment)' was rephrased to 'all-cause mortality' for clarity.

\section{INDEX TERMS}

\section{Medical Subject Headings (MeSH)}

Cause of Death; Early Detection of Cancer; Neoplasms [*complications; *diagnosis; diagnostic imaging; mortality]; Positron Emission Tomography Computed Tomography; Pulmonary Embolism [diagnostic imaging; * etiology; mortality]; Randomized Controlled Trials as Topic; Risk Factors; Venous Thromboembolism [diagnostic imaging; *etiology; mortality]; Venous Thrombosis [diagnostic imaging; *etiology; mortality]

\section{MeSH check words}

Humans

Effect of testing for cancer on cancer- and venous thromboembolism (VTE)-related mortality and morbidity in people with unprovoked 